Article

\title{
Design, Fabrication, and Testing of a Bulk Micromachined Inertial Measurement Unit
}

\section{Honglong Chang *, Qiang Shen, Zhiguang Zhou, Jianbing Xie, Qinghua Jiang and Weizheng Yuan}

Micro and Nano Electromechanical System Laboratory, Northwestern Polytechnical University, 127\#, Youyi West Road, Xi’an, Shaanxi, China; E-Mail: yuanwz@nwpu.edu.cn (W.-Z.Y.)

* Author to whom correspondence should be addressed; E-Mail: changhl@nwpu.edu.cn; Tel.: +86-29-88492841; Fax: +86-29-88495102.

Received: 22 February 2010; in revised form: 17 March 2010 / Accepted: 6 April 2010 / Published: 14 April 2010

\begin{abstract}
A bulk micromachined inertial measurement unit (MIMU) is presented in this paper. Three single-axis accelerometers and three single-axis gyroscopes were simultaneously fabricated on a silicon wafer using a bulk micromachining process; the wafer is smaller than one square centimeter. In particular, a global area optimization method based on the relationship between the sensitivity and layout area was proposed to determine the layout configuration of the six sensors. The scale factors of the $\mathrm{X} / \mathrm{Y}$-axis accelerometer and Z-axis accelerometer are about $213.3 \mathrm{mV} / \mathrm{g}$ and $226.9 \mathrm{mV} / \mathrm{g}$, respectively. The scale factors of the $\mathrm{X} / \mathrm{Y}$-axis gyroscope and Z-axis gyroscope are about $2.2 \mathrm{mV} / \% \mathrm{~s}$ and $10.8 \mathrm{mV} / \%$ s, respectively. The bias stability of the $\mathrm{X} / \mathrm{Y}$-axis gyroscope and the $\mathrm{Z}$-axis gyroscope are about $2135 \mathrm{deg} / \mathrm{h}$ and $80 \mathrm{deg} / \mathrm{h}$, respectively. Finally, the resolutions of $\mathrm{X} / \mathrm{Y}$ axis accelerometers, $\mathrm{Z}$-axis accelerometers, $\mathrm{X} / \mathrm{Y}$-axis gyroscopes, and $\mathrm{Z}$-axis gyroscopes are $0.0012 \mathrm{~g} / \sqrt{\mathrm{Hz}}, 0.0011 \mathrm{~g} / \sqrt{\mathrm{Hz}}, 0.314^{\circ} / \mathrm{s} / \sqrt{\mathrm{Hz}}$, and $0.008^{\circ} / \mathrm{s} / \sqrt{\mathrm{Hz}}$, respectively.
\end{abstract}

Keywords: MEMS; MIMU; bulk micromachining; gyroscope; accelerometer

\section{Introduction}

Inertial navigation requires a measurement with six degrees of freedom (DOF) in three-dimensional space, namely the ability to move forward or backward, up or down, left or right (translation in three 
perpendicular axes) combined with rotation about three perpendicular axes (pitch, yaw, roll). A micromachined inertial measurement unit (MIMU) is used to output signals proportional to the rotation and translational motion of a carrier in six DOFs from, respectively, micromachined angular rate sensors and acceleration sensors. Traditionally, these separated inertial sensors are mechanically mounted orthogonally in one or two substrates to output the three-axis angular rate and acceleration measurement signals [1]. In this mechanical assembling process, it is difficult to achieve exact mutual orthogonality between the sensors. Orthogonality aberrations degrade the accuracy of the subsequent processes, such as attitude determination or inertial navigation. A variety of multi-axis inertial sensors, such as tri-axis micro gyroscopes [2-4] or tri-axis micro accelerometers [5-8], can alleviate this misalignment problem in MIMU. Moreover, such technology allows the MIMU to be even smaller because the multi-axis sensing only requires one inertial mass. However, the cross-axis coupling within the multi-axis sensor limits the performance of the sensor. Designing a tri-axis sensor with only one inertial mass is a challenging task and requires a creative, clever design.

Integrated MIMU (IMIMU) technology can avoid the misalignment problem without tri-axis sensors. In IMIMU, different single-axis inertial sensors are fabricated simultaneously on a single chip with a surface or bulk micromachining process. Thus, the mutual orthogonality in IMIMU is inherently guaranteed by the design. Additionally, compared with tri-axis sensors, a single-axis inertial sensor is more rugged, and easier to design. Furthermore, cross coupling within a tri-axis sensor is successfully avoided. The first IMIMU was implemented using a surface micromachining process in 1998 [9]. It integrates three accelerometers, a dual-axis gyroscope, and a Z-axis gyroscope into a 1-cm ${ }^{2}$ chip, including the interface circuitry. Luo Hao integrated two accelerometers and a gyroscope into a single chip using a surface process in 2003 [10]. It did not include an X/Y-axis gyroscope or a Z-axis accelerometer. Currently, surface micromachined IMIMUs have been commercialized successfully by Analog Devices, Inc (Norwood, MA, USA).

However, there is no report on bulk micromachined IMIMU so far. The major difficulty is the lack of a mature monolithic bulk micromachining process. Some monolithic bulk processes have emerged recently [11-15]. Unfortunately, they are not mature enough to realize a complex device like IMIMU. It is widely accepted that the bulk process could achieve better performance than the surface process for the inertial sensor. Today, inertial sensors with the highest accuracy [16,17] are nearly all fabricated by bulk micromachining process, where the larger proof mass can reduce mechanical noise to improve performance. Therefore, people usually utilize a two-chip integration scheme to realize bulk micromachined MIMU. In this two-chip approach, the six mechanical sensing elements are simultaneously fabricated on a chip and packaged with a circuit chip that reads out the various signals and generates the corresponding signal. Donato Cardarelli proposed a two-level conceptual MIMU design scheme based on the standard dissolved wafer process in 2002 [18]. However, no further fabrication or test results with this bulk micromachined MIMU have been reported. In our previous work [19], we established a two-chip MIMU using a bulk micromachining process. However, the yield rate of fabricating the mechanical chip is very low, which partially explains why there has not been a commercial bulk micromachined MIMU until now.

There are many difficulties when fabricating the six inertial sensors simultaneously through the bulk micromachining process. First, there is a tradeoff between area limitation and sensor performance. For a single inertial sensor, greater area usually means better performance because the performance is 
usually proportional to the inertial mass. However, greater area reduces the accuracy of micromachining process. In our bulk process, the minimum line width is $2 \mu \mathrm{m}$ when the layout area is less than $8 \mathrm{~mm} \times 8 \mathrm{~mm}$. However, the minimum line width will become $10 \mu \mathrm{m}$ when the layout area is larger than $10 \mathrm{~mm} \times 10 \mathrm{~mm}$. Therefore, a trade-off must be made to optimize a total of six sensors in a limited area. Secondly, the reactive ion etching (RIE) lag effect [20,21], which does not appear as a major problem in the surface micromachining, and notching effect [22] in deep RIE (DRIE) are challenges when generating a bulk micromachined MIMU. The six sensors inevitably have different line widths. Consequently, different etching depths caused by the RIE lag effect definitely hurt the performance of inertial sensors. Finally, the residual stress caused by the anodic bonding and chemical mechanical planarization (CMP) in the bulk process [23-24] cause a large mode mismatch for gyroscopes, which is a fatal bug for gyroscopes. In this paper, we present solutions to these problems to establish a bulk micromachined two-chip MIMU based on our previous work.

\section{Topologies Selection for the Inertial Sensors Based on a Two-Structure-Layer Bulk Process}

The proposed MIMU integrates two chips, as shown in Figure 1, where the letters A and G represent the accelerometer and gyroscope, respectively. The mechanical sensing element chip consists of sensing structures for six single-axis inertial sensors, i.e., three accelerometers and three gyroscopes. While the interface circuit chip consists of the six interface circuits that match the corresponding sensors. The two chips are packaged together to form the final MIMU device.

Figure 1. Schematic of the two-chip integration scheme.

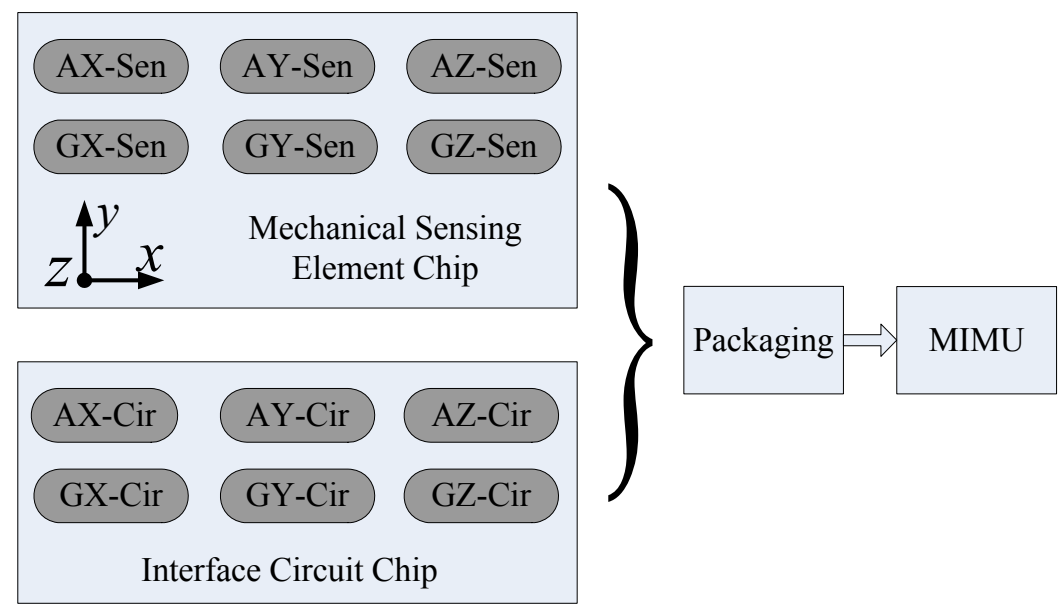

The first step when designing the bulk micromachined MIMU is to determine its topology for each single-axis inertial sensor based on a bulk process. The sandwich process or other processes with more than three structure layers are very complex and greatly reduce the yield rate to MIMU. A two-structure-layer process, as shown in Figure 2, is used to design the MIMU. Fabrication begins with a P-type single-crystalline silicon wafer. First, the photo resist (PR) is coated on the wafer to form the mask of anchors, as shown in step (a). In step (b), inductively coupled plasma (ICP) etching is used to etch shallow trenches to form anchors, and in step (c), PR is coated on the glass wafer. In step (d), a deep trench is wet etched on the glass wafer to increase the distance between the proof mass and the 
substrate. In step (e), a layer of metal is sputtered on the glass to form electrodes. In step (f), anodic bonding is used to bond the glass and silicon wafer together. At this step chemical mechanical polishing is used to reduce the thickness of the silicon wafer to meet the actual demand. In step (g), PR is coated on the back side of the silicon wafer. Finally, in step (h), ICP is used again to form moving structures, such as comb drives or damping holes.

It is obvious that the major process flow is similar to our previous one [19]. However, some improvements have been proposed to ensure an acceptable MIMU yield rate. The thickness of the proof mass was reduced to 65 microns from 80 microns. One additional mask was provided to add a trench in the glass to increase the distance between the proof mass and the substrate for some sensors, including the $\mathrm{Z}$-axis gyroscope and $\mathrm{X} / \mathrm{Y}$-axis accelerometer. Thus, the slide film damping in these devices is greatly reduced to improve the quality factors for Z-axis gyroscopes because the MIMU is packaged at one atmosphere.

Figure 2. The process flow for the mechanical sensing element chip.

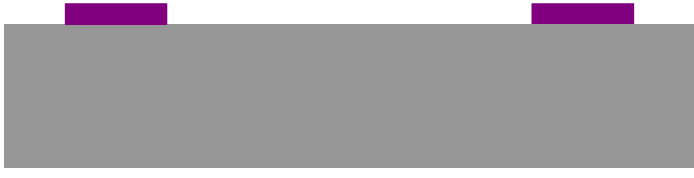

(a) Pattern the anchor with PR

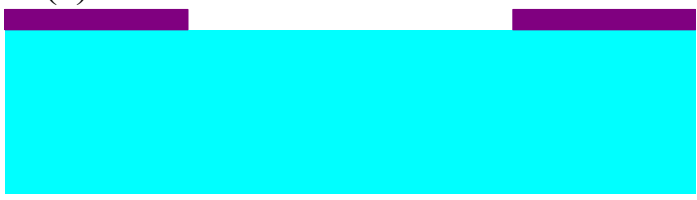

(c) Pattern the glass with PR

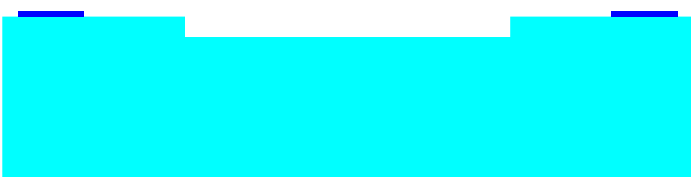

(e) Sputtering and lift off

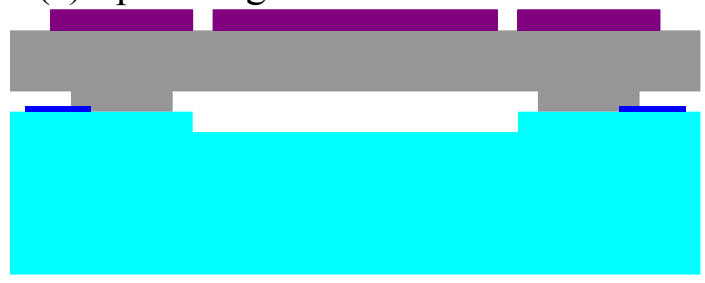

(g) Pattern the structure with PR

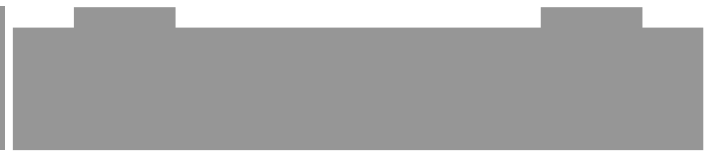

(b) Shallow trench etching by ICP

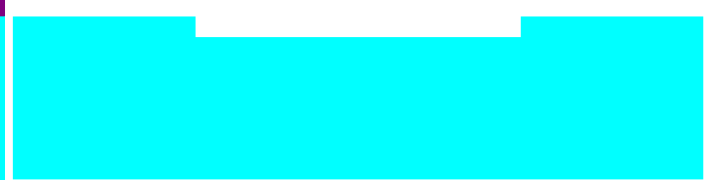

(d) Wet etch by HF solution

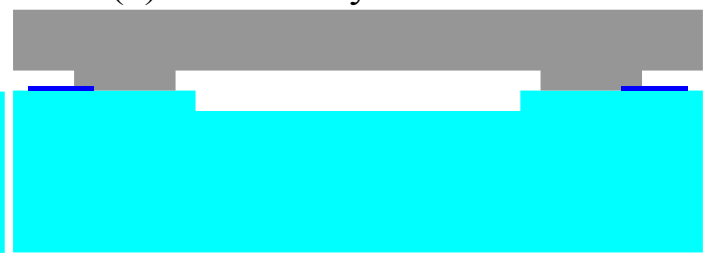

(f) Anodic bonding

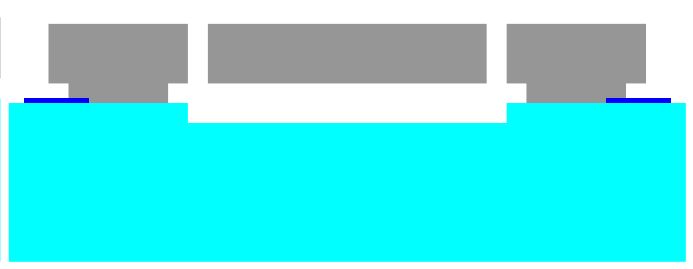

(h) Deep trench etching by ICP

In this study, we use the most typical topologies for inertial sensors instead of novel designs to ensure a better yield rate because they have been verified in many ways. There are many typical topologies for accelerometers [25-30]. Most lateral accelerometers fabricated by surface or bulk micromachining processes can be used as the $\mathrm{X} / \mathrm{Y}$-axis accelerometer in the proposed MIMU. The vertical accelerometers, which require the sandwich process, cannot be used as the Z-axis accelerometer in the proposed MIMU. Finally the topologies of the accelerometers are chosen as 
shown in Figure 3. After experimental verification with the previous MIMU, the topologies are proved to be effective and are still used in this version of MIMU.

Figure 3. (a) The topology of the $\mathrm{X} / \mathrm{Y}$-axis accelerometer. (b) The topology of the Z-axis accelerometer.

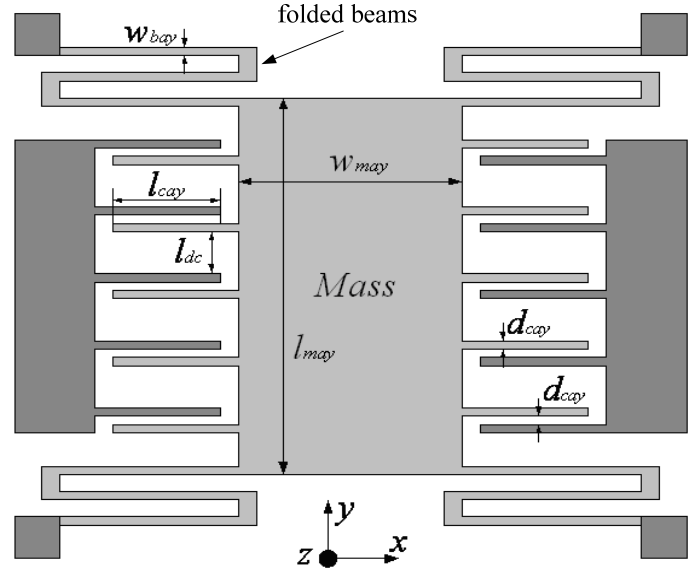

(a)

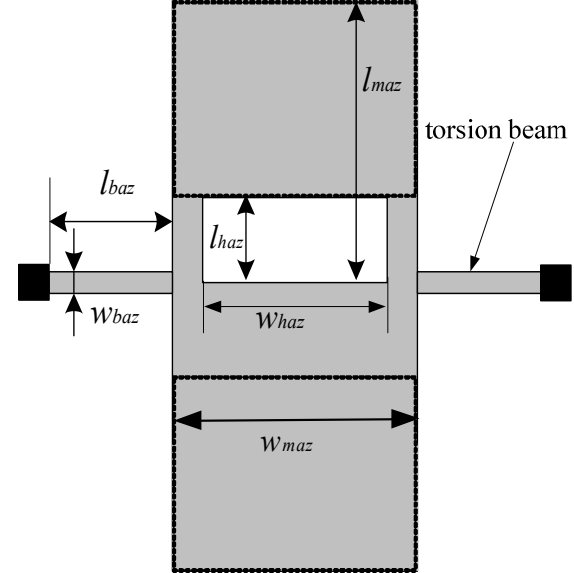

(b)

There are also many typical topologies for gyroscopes [31-36] that are compatible with the above-mentioned process flow. In the current version, there are many essential improvements on gyroscopes to increase the yield rate of the MIMU. The vibrating wheel gyroscope in the previous version was difficult to fabricate. Thus, we used the tuning fork gyroscope instead [31]. The Z-axis gyroscope with interdigitated electrodes in the sense mode [32] was difficult to fabricate because the large metal electrodes in the glass wafer are hard to remove. Therefore, we used a symmetrical Z-axis gyroscope topology [33] to replace it. Finally, the topologies of the gyroscopes are chosen as shown in Figure 4.

Figure 4. (a) $\mathrm{X} / \mathrm{Y}$-axis gyroscope topology in the two-chip MIMU. (b) Z-axis gyroscope topology in the two-chip MIMU.

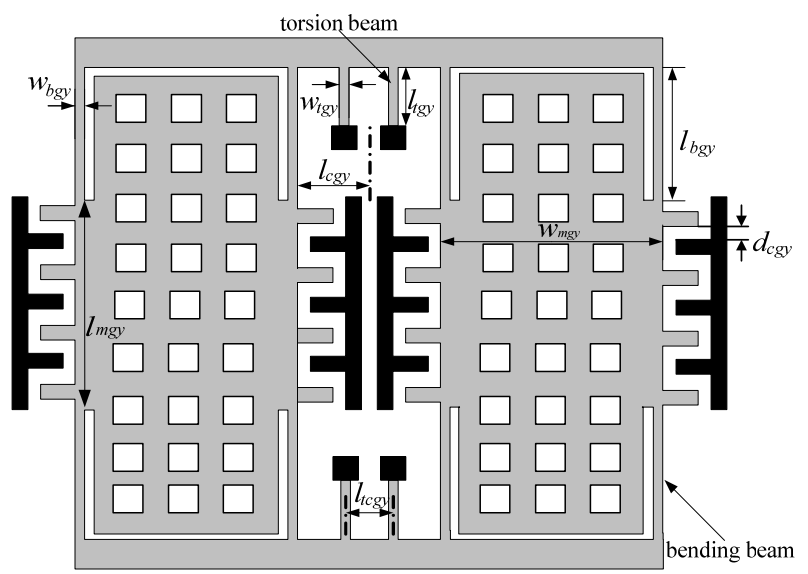

(a)

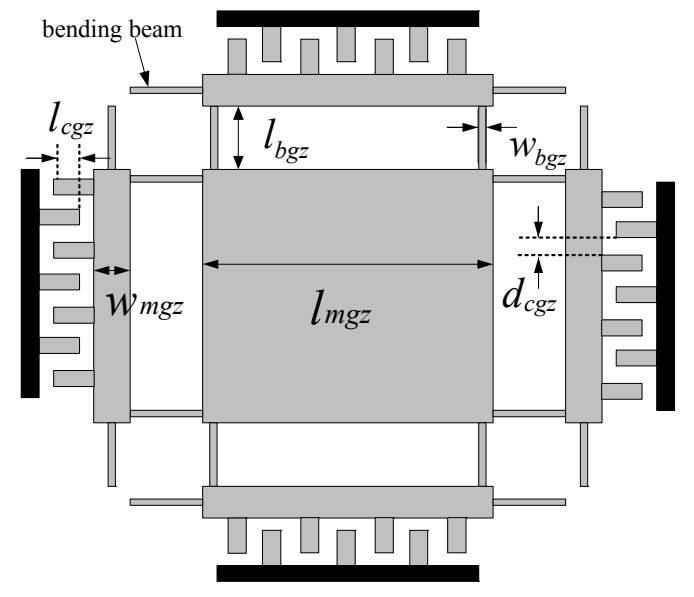

(b) 


\section{Layout Optimization for the Mechanical Sensing Elements}

After choosing a feasible topology for each inertial sensor, we must determine the dimensions for each sensor. However, the MIMU consists of six separated inertial sensors, which means the usual device optimization approaches, such as a genetic algorithm (GA) [36] or simulated annealing algorithm (SAA) [37], are not suitable to be applied directly to MIMU design. Therefore, area occupations for each sensor should be determined first before the detailed design for the single sensor. In this paper, we propose an area optimization approach to establish the layout configuration for MIMU.

\subsection{Common Geometry Patterns for MIMU}

To alleviate the RIE lag effect in the bulk micromachining process, the geometry patterns for the six sensors should be set as close as possible. As a result, the inertial masses, the suspension beams, the damping holes, and the comb capacitors should be given a very similar geometry pattern with very close dimensions, which we call common geometry patterns.

Some common geometry patterns are simply determined by the process rules. For example, the gap and the width of comb fingers in comb drives or comb capacitors are both set as 4 microns to obtain the maximum capacitance in a limited area. In addition to these two parameters, we also set the overlap and the length of comb fingers in an identical configuration as shown in Table 1.

Table 1. The common geometry configuration for MIMU.

\begin{tabular}{cc}
\hline Parameters & Values \\
\hline The overlap of comb fingers & $80 \mu \mathrm{m}$ \\
Length of comb fingers & $160 \mu \mathrm{m}$ \\
Width of comb fingers & $4 \mu \mathrm{m}$ \\
Gap between comb fingers & $4 \mu \mathrm{m}$ \\
Gap between the structure and substrate & $3 \mu \mathrm{m}$ \\
Thickness of structure & $65 \mu \mathrm{m}$ \\
Length of torsional beams & $\leq 300 \mu \mathrm{m}$ \\
Width of torsional beams & $\geq 20 \mu \mathrm{m}$ \\
Length of bending beams & $\leq 550 \mu \mathrm{m}$ \\
Width of bending beams & $\geq 10 \mu \mathrm{m}$ \\
\hline
\end{tabular}

Some common patterns, such as resonant frequency and inertial mass, are mainly determined by the requirements of the sensor. It is important to choose a common resonant frequency for these inertial sensors according to the requirements because the sensitivity depends on it. In this paper, $4,000 \mathrm{~Hz}$ is selected initially for these sensors to ensure both a large sensitivity and adequate resistance to disturbances. The area of the inertial mass is also an important parameter because it is related to either the initial capacitance or capacitance variance. It is mainly determined by the capacitance detection capability. Consequently, the suspension beams for these inertial sensors also have a common configuration initially. Two kinds of beams largely determine the spring constant of the corresponding working modes: bending beams and torsional beams, which are used to determine the spring constant 
of the $\mathrm{Z}$-axis accelerometer and the sense mode of $\mathrm{X} / \mathrm{Y}$-axis gyroscope. We provide a list of initial empirical values for these suspension beams in Table 1. These common geometry patterns not only alleviate the RIE lag effect but also simplify the deduction of the relationship between sensitivity and layout area.

\subsection{Sensitivity versus Layout Area}

Because there is an area limitation to design inertial sensors using the bulk micromachining process, it is useful to find the relationship between the performance and the area. We deduce a simplified relationship between the sensitivity and the layout area with some assumptions and some available dimensions.

The sensitivity and resonant frequency of the $\mathrm{X} / \mathrm{Y}$-axis accelerometer can be described as the following:

$$
\begin{gathered}
S_{a y}=\frac{\Delta c}{a}=\frac{1}{\omega_{a y}{ }^{2}} n \frac{\varepsilon_{0} l_{\text {cay }} h}{d_{c a y}{ }^{2}} \\
\omega_{a y}=\sqrt{\frac{4 E w_{\text {bay }}{ }^{3}}{\rho w_{\text {may }} l_{\text {may }} l_{\text {bay }}{ }^{3}}}
\end{gathered}
$$

where $l_{\text {may }}, w_{\text {may }}, l_{\text {bay }}, w_{\text {bay }}, l_{\text {cay }}, d_{\text {cay }}$ are shown in Figure 3 (a); $l_{\text {may }}$ and $w_{\text {may }}$ are the length and width of the inertial mass of the $\mathrm{X} / \mathrm{Y}$-axis accelerometer; $l_{\text {bay }}$ and wbay are the length and width of the bending beams; $l_{c a y}$ is the overlap of the comb fingers; $d_{c a y}$ is the gap between capacitor plate; $n$ is the number of comb fingers; $h$ is the thickness of the structure; $\omega_{a y}$ is the natural resonant frequency of the $\mathrm{X} / \mathrm{Y}$-axis accelerometer; $\varepsilon_{0}$ is the dielectric constant of the air; $E$ is Young's modulus of silicon; and $\rho$ is density of silicon.

It can be seen from Equation (1) that the sensitivity of the $\mathrm{X} / \mathrm{Y}$-axis accelerometer is proportional to the number of comb fingers, which is evident in some parameters, such as the overlap, thickness and gap, which are shown in Table 1 . As for the biased comb capacitors, $l_{d c}$ is usually set to be much bigger than the gap $d_{c a y}$; here, $l_{d c}=d_{c a y}$. To ensure the inertial mass of the accelerometer is large enough, we assumed that the area occupied by the biased comb capacitors is about a quarter of the total area of the accelerometer. Therefore, we can assume that the sensitivity of the $\mathrm{X} / \mathrm{Y}$-axis accelerometer is only related to its area. To further simplify the relationship, we assumed that the area of the $\mathrm{X} / \mathrm{Y}$-axis accelerometer is represented by an equivalent square with an equivalent side length. Consequently, the equivalent side length for $\mathrm{X} / \mathrm{Y}$-axis accelerometer is approximated as $L_{a y}=\sqrt{2 \times n \times l_{c a y} \times d_{c a y} \times 4 \times 4}$ when the area occupied by the fingers is ignored.

As for the Z-axis accelerometer, the sensitivity and resonant frequency formulas are:

$$
S_{z a}=\frac{\Delta C}{a}=\frac{3}{2 \omega_{z a}{ }^{2}} \frac{\frac{w_{\text {haz }}}{w_{\text {maz }}\left(\frac{l_{\text {haz }}}{l_{\text {maz }}}\right)^{2}}\left\{2-\left(\frac{l_{\text {haz }}}{l_{\text {maz }}}\right)^{3}+\left(1-\frac{w_{\text {haz }}}{w_{\text {maz }}}\right)\left(\frac{l_{\text {haz }}}{l_{\text {maz }}}\right)^{3}\right\}}{\varepsilon l_{\text {maz }} w_{\text {maz }}\left(1-\left(\frac{l_{\text {haz }}}{l_{\text {maz }}}\right)^{2}\right)}
$$




$$
\omega_{z a}=\sqrt{\frac{6 G \beta w_{b a z}{ }^{3}}{\rho l_{b a z} w_{\text {maz }} l_{\text {maz }}^{3}\left(2-\left(\frac{l_{h a z}}{l_{\text {maz }}}\right)^{3}+\left(1-\frac{w_{\text {haz }}}{w_{\text {maz }}}\right)\left(\frac{l_{\text {haz }}}{l_{\text {maz }}}\right)^{3}\right)}}
$$

where $l_{b a z}, w_{b a z}, l_{\text {maz }}, w_{\text {maz }}, l_{\text {haz }}$, whaz are shown in Figure 3 (b); $l_{b a z}$ and $w_{b a z}$ are the length and width of the bending beams, respectively; $l_{\operatorname{maz}}$ and $w_{\operatorname{maz}}$ are the length and width of the inertial mass, respectively; $l_{h a z}$ and $w_{h a z}$ are the length and width of the hole, respectively; $d_{0}$ is the gap between structure and the substrate; $\omega_{z a}$ is the natural resonant frequency of the Z-axis accelerometer; $G$ is torsion modulus; and $\beta$ is torsion coefficient.

It can be seen from Equation (3) that the sensitivity of the Z-axis accelerometer is related to the area of the inertial mass $\left(l_{\text {maz }} \times w_{\text {maz }}\right)$ and the ratio $l_{\text {haz }} / l_{\text {maz }}$. The sensitivity reaches its maximum when the ratio is about 0.7 . Furthermore, in order to ensure a large stiffness in the Z-axis direction, we set $w_{\text {haz }}=0.5 \times w_{\text {maz }}$. Therefore, we can obtain an equivalent side length for the Z-axis accelerometer, $L_{a z}=\sqrt{2 w_{\operatorname{maz}} \times l_{\text {maz }}}$, with a similar assumption.

For the $\mathrm{X} / \mathrm{Y}$-axis gyroscope, the sensitivity and resonant frequency formulas are:

$$
\begin{gathered}
S_{g y}=4 \times\left(\frac{39}{64}\right)^{2} \frac{\varepsilon^{2} \rho h^{2} l_{m g y} w_{m g y}{ }^{2}\left(l_{m g y}+2 l_{b g y}\right)^{2}}{\omega_{d g y}\left(\mu^{*} l_{c g y} h l_{m g y} d_{0}{ }^{2}+\mu^{*} w_{m g y}\left(l_{m g y}+2 l_{b g y}\right) d_{c g y}{ }^{2} d_{0}\right) c_{s}} V_{p} v_{a} \\
\omega_{d g y}=\sqrt{\frac{256 E w_{b g y}{ }^{3}}{39 \rho\left(l_{m g y}+2 l_{b g y}\right) w_{m g y} l_{b g y}{ }^{3}}} \\
\omega_{s g y}=\sqrt{\frac{128 G \beta w_{t g y}{ }^{3}}{39 \rho w_{m g y} l_{t g y}\left(l_{m g y}+2 l_{b g y}\right)\left(\frac{w_{m g y}}{2}+l_{c g y}\right)^{2}}}
\end{gathered}
$$

where $l_{m g y}, w_{m g y}, l_{b g y}, w_{b g y}, l_{t g y}, w_{t g y}, l_{c g y}$ are shown in Figure 4 (a); $l_{t g y}$ and $w_{t g y}$ are the length and width of the torsion beams, respectively; $d_{c g y}$ is the width of the comb fingers; $d_{0}$ is the gap between structure and substrate; $h$ is thickness of the structure; $\omega_{d g y}$ is the natural resonant frequency of drive mode; $\omega_{s g y}$ is natural resonant frequency of sense mode; $\rho$ is the density of the silicon; $\mu^{*}$ is the dynamic viscosity of the air; $V_{p}$ is DC voltage; and $v_{a}$ is the AC voltage.

It can be seen from Equation (5) that the sensitivity of the $\mathrm{X} / \mathrm{Y}$-axis gyroscope is related to its area of inertial mass because the beam dimensions of the beams were given a group of initial values. An equivalent side length for the $\mathrm{X} / \mathrm{Y}$-axis gyroscope can be given as $L_{g y}=\sqrt{2 \times\left(w_{m g y}+l_{c g y}\right)\left(l_{m g y}+2 l_{b g y}\right)}$.

As for the Z-axis gyroscope, the sensitivity and resonant frequency formulas are :

$$
S_{g z}=2 \rho \frac{\varepsilon_{0}{ }^{2}}{\omega_{g z}} \frac{h^{3}}{\left(\frac{\mu^{*} l_{c g z} h}{l_{m g z}}+\frac{\mu^{*} d_{c g z}^{2}}{d_{0}}\right)^{2}} V_{p} v_{a}
$$




$$
\omega_{g z}=\sqrt{\frac{8 E w_{b g z}{ }^{3}}{\rho l_{m g z}{ }^{2} l_{b g z}{ }^{3}}}
$$

where $l_{m g z}, w_{m g z}, l_{b g z}, w_{b g z}$ are shown in Figure $4(\mathrm{~b}) ; d_{c g z}$ is the width of the comb fingers; $h$ is thickness of the structure; $\omega_{g z}$ is the natural resonant frequency of the Z-axis gyroscope; and $V_{p}$ is DC voltage; $v_{a}$ is $\mathrm{AC}$ voltage.

It can be seen from Equation (8) that the sensitivity of the Z-axis gyroscope is related to its area of inertial mass because the beam dimensions were given a group of initial values. An equivalent side length for Z-axis gyroscope can be given as $L_{g z}=l_{m g z}+2 \times\left(l_{b g z}-50\right)$.

All the formulas for the equivalent side length are listed in Table 2. Based on these formulas, the sensitivity is dependent on just one variable related to its area. We can use this relationship in our global optimization to determine the layout configuration for these six sensors.

Table 2. The side length of the equivalent square for sensors in the MIMU.

\begin{tabular}{|c|c|c|}
\hline Name of Sensors & Side Length & Notes \\
\hline $\mathrm{X} /$ Y-axis Accelerometer & $L_{a x}=\sqrt{2 \times n \times l_{c a y} \times d_{c a y} \times 4 \times 4}$ & $l_{c a y}=80 \mu m ; d_{c a y}=4 \mu m$ \\
\hline Z-axis Accelerometer & $L_{a z}=\sqrt{2 w_{m a z} \times l_{m a z}}$ & $l_{m a z}=w_{m a z}$ \\
\hline X/Y-axis Gyroscope & $L_{g y}=\sqrt{2 \times\left(w_{m g y}+l_{c g y}\right)\left(l_{m g y}+2 l_{b g y}\right)}$ & $w_{m g y}=l_{m g y} ; l_{c g y}=500 \mu m ; l_{b g y}=550$ \\
\hline Z-axis Gyroscope & $L_{g z}=l_{m g z}+2 \times\left(l_{b g z}-50\right)$ & $l_{b g z}=550$ \\
\hline
\end{tabular}

\subsection{Global Optimization Process for MIMU}

A global optimization approach is proposed to determine the layout configuration for inertial sensors in MIMU, as shown in Figure 5. The optimization begins with the requirements analysis. The requirements usually reflect the sensitivity when considering the capacitance detection capability. Then, we can use the relationship between the sensitivity and the equivalent side length to get a rough layout. The layout configuration must be adjusted further according to the relationship between the resonant frequency and the area. Then, we can get a finer layout configuration for these six inertial sensors. Given the layout configuration obtained in the global optimization stage, we can design each single sensor carefully, as usual.

As for our design case, the accuracy of the accelerometers and gyroscopes are expected to reach a navigation level [38], in which the resolution of accelerometers is about $10^{-6} \mathrm{~g}$ and the resolution of gyroscopes is about $10^{-4} \%$ s. If the detection capability of the capacitive interface circuit can reach $10^{-19} \mathrm{~F}$, then the sensitivity of gyroscopes should be larger than $10^{-15} \mathrm{~F} / \%$ s and the sensitivity of the accelerometers should be larger than $10^{-14} \mathrm{~F} / \mathrm{g}$. Before the optimization, the natural resonant frequency of each inertial sensor was chosen as $4,000 \mathrm{~Hz}$. Using the relationship between the sensitivity and equivalent side length, as plotted in Figure 6, we obtain a rough layout configuration in which the equivalent side length was determined to be $3,000-3,500 \mu \mathrm{m}$. This area satisfies the sensitivity requirements for both gyroscopes and accelerometers. However it is difficult to assign six sensors with a side length of about $3,500 \mu \mathrm{m}$ within a $10,000 \mu \mathrm{m} \times 10,000 \mu \mathrm{m}$ square. Therefore, we 
reduced the area of the accelerometers. To make the accelerometers meet the sensitivity requirements, the natural resonant frequency of the accelerometers must be reduced. Therefore, we generated a new layout configuration based on Figure 7, in which the equivalent side length of accelerometers was about $1,500-2,000 \mu \mathrm{m}$. Some available material or process parameters used in the optimization are listed in Table 3.

Figure 5. The flow of the proposed global optimization approach.

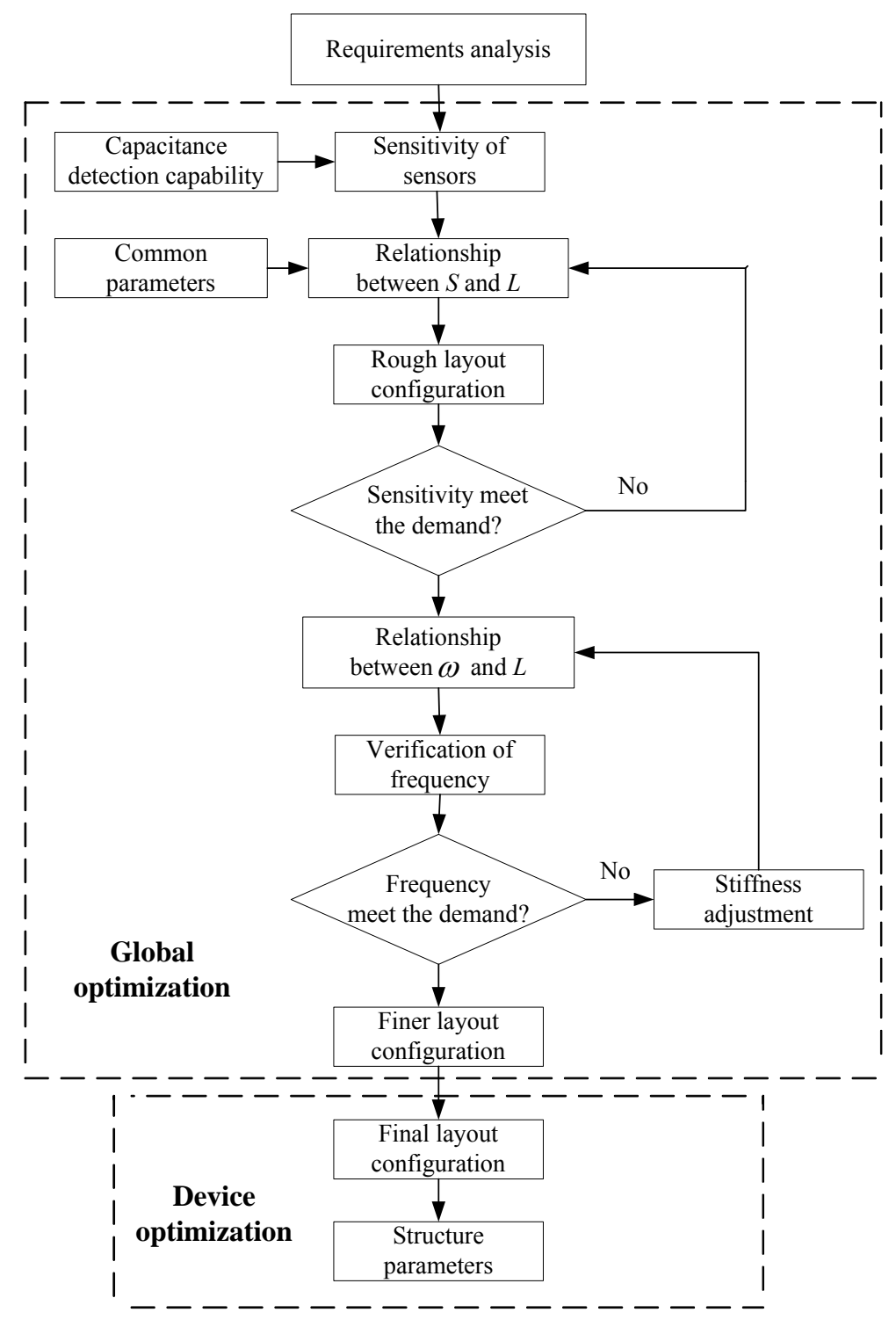

Table 3. The common parameters for MIMU optimization.

\begin{tabular}{cc}
\hline Parameters & Values \\
\hline The material density of the silicon & $2.33 \times 10^{3} \mathrm{~kg} / \mathrm{m}^{3}$ \\
Young's modulus & $130 \mathrm{Gpa}$ \\
Poisson's ratio & 0.22 \\
Shear modulus & $53.3 \mathrm{GPa}$ \\
Packaging pressure & $1 \mathrm{~atm}$ \\
Area limit for MIMU & $10 \mathrm{~mm} \times 10 \mathrm{~mm}$ \\
\hline
\end{tabular}


Figure 6. The sensitivity versus layout area; the natural frequency of each inertial sensor is chosen as $4,000 \mathrm{~Hz}$.

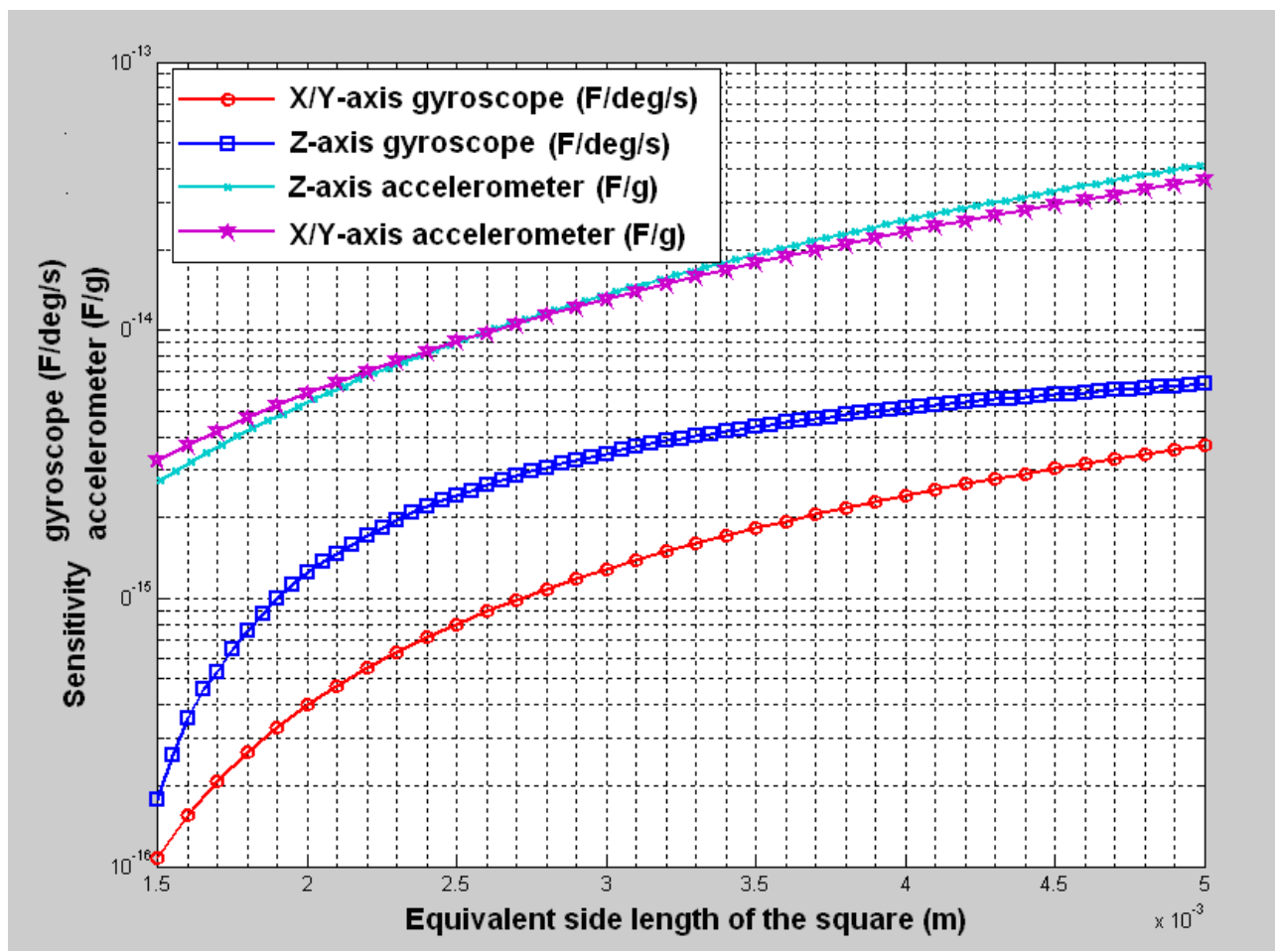

Figure 7. The sensitivity versus layout area; the natural frequency of the accelerometers is $2,000 \mathrm{~Hz}$, and the natural frequency of the gyroscopes is $4,000 \mathrm{~Hz}$.

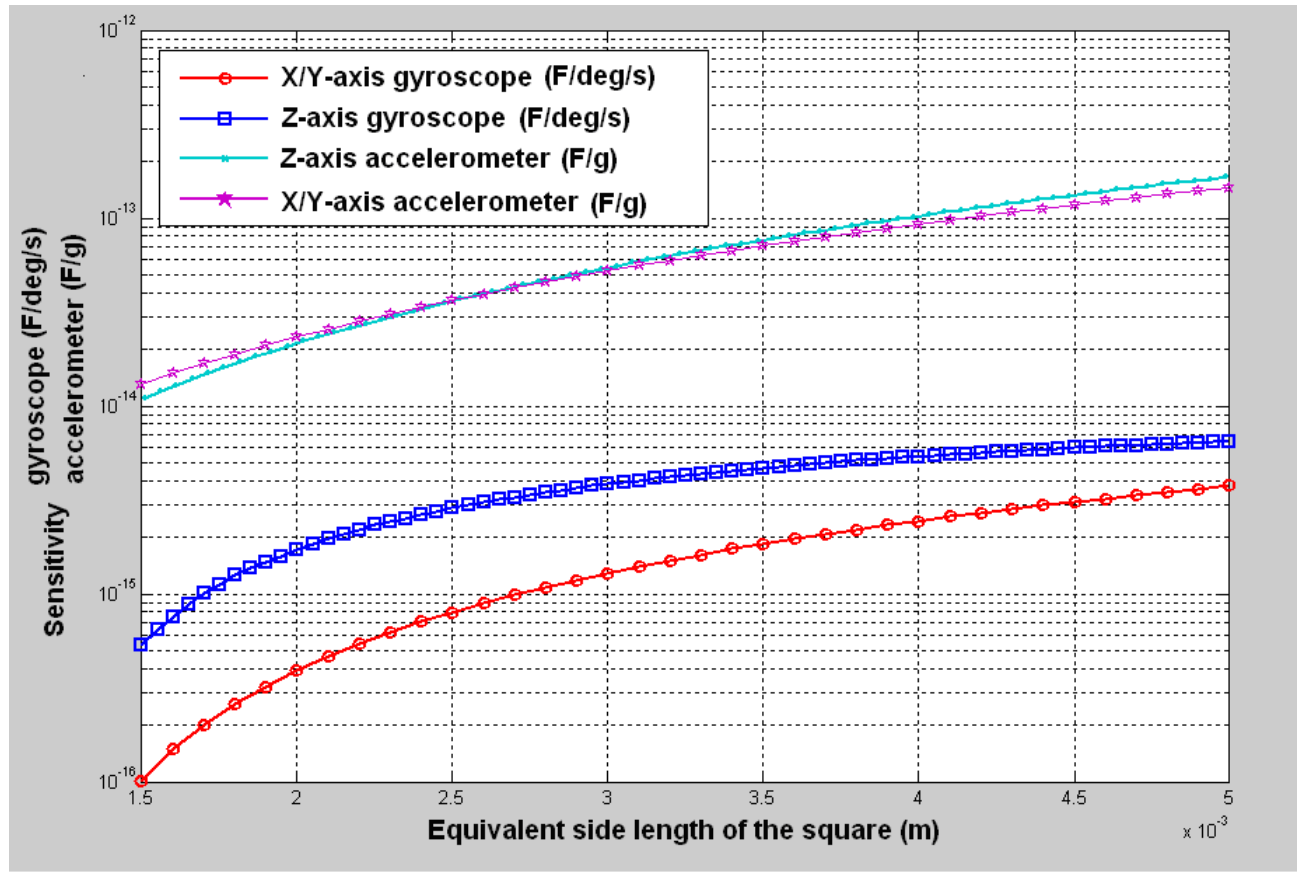


Figure 8. The natural resonant frequencies of the inertial sensors versus the layout area.

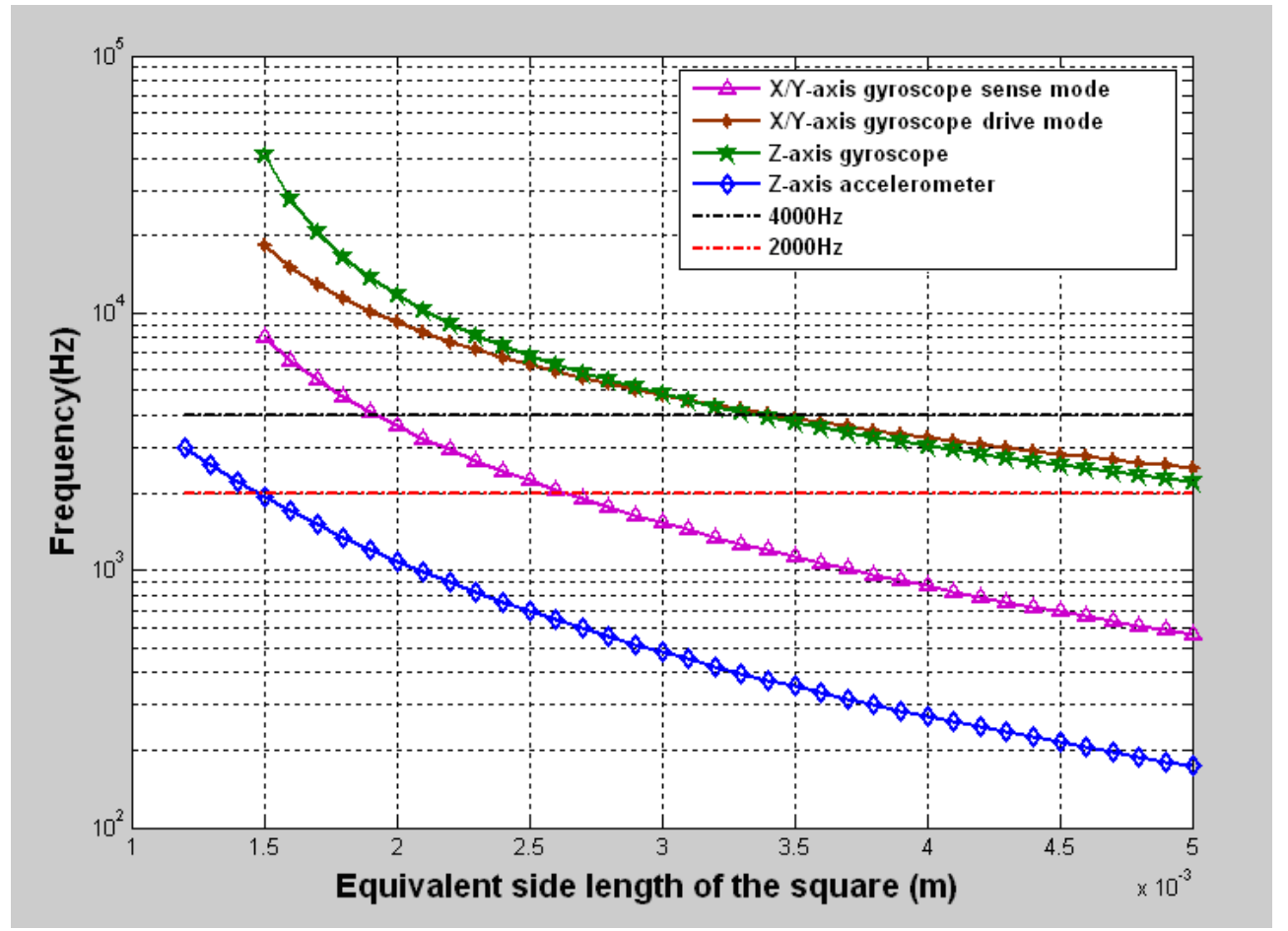

After getting the rough layout configuration, we need to prove that the natural resonant frequencies meet the requirements using the equivalent side length in the rough layout configuration. The actual natural resonant frequency of the inertial sensor versus the layout area is plotted in Figure 8. It is obvious that the frequency of the Z-axis gyroscope is $4,000 \mathrm{~Hz}$ when the equivalent side length is about 3,000 $\mu \mathrm{m}$. However the frequency of the sense mode for the $\mathrm{X} / \mathrm{Y}$-axis gyroscope is not more than $2,000 \mathrm{~Hz}$. We simply increased the frequency to $4,000 \mathrm{~Hz}$ by reducing the length of the torsional beams. The $\mathrm{Z}$-axis accelerometer meets the frequency requirements for the given area. Therefore, we set the equivalent side length of the $\mathrm{Z}$-axis accelerometer to be about $1,500 \mu \mathrm{m}$. The $\mathrm{X} / \mathrm{Y}$-axis accelerometer took the folded beams. Therefore, the stiffness adjustment could be made easily to meet the frequency requirements without considering the equivalent side length. Thus, we do not plot the $\mathrm{X} / \mathrm{Y}$-axis accelerometer here.

\subsection{Device Optimization Results for MIMU}

After obtaining the global layout configuration for the six inertial sensors, the various device optimization approaches can be used to determine the final layout of MIMU within the given area. Because the design in this stage is very common, we skip the details and give the final dimensions of MIMU in Tables 4-7. We obtained the final layout configuration of the mechanical chip as shown in Figure 9 and Table 8. 
Table 4. Dimensions of $\mathrm{X} / \mathrm{Y}$-axis accelerometer.

\begin{tabular}{|c|c|c|c|}
\hline$l_{\text {may }}$ & $2,000 \mu \mathrm{m}$ & $d_{\text {cay }}$ & $4 \mu \mathrm{m}$ \\
\hline$w_{\text {may }}$ & $780 \mu \mathrm{m}$ & $l_{\text {cay }}$ & $80 \mu \mathrm{m}$ \\
\hline Folded beams & \multicolumn{2}{|c|}{ Consists of nine beams, each with a length of $360 \mu \mathrm{m}}$. \\
\hline
\end{tabular}

Table 5. Dimensions of Z-axis accelerometer.

\begin{tabular}{|c|c|c|c|}
\hline$l_{b a z}$ & $170 \mu \mathrm{m}$ & $w_{\operatorname{maz}}$ & $1,200 \mu \mathrm{m}$ \\
\hline$w_{b a z}$ & $20 \mu \mathrm{m}$ & $l_{\text {haz }}$ & $1,300 \mu \mathrm{m}$ \\
\hline$w_{\text {haz }}$ & $540 \mu \mathrm{m}$ & $l_{\text {maz }}$ & $2,000 \mu \mathrm{m}$ \\
\hline
\end{tabular}

Table 6. Dimensions of X/Y-axis gyroscope.

\begin{tabular}{|c|c|c|c|}
\hline$l_{b g y}$ & $530 \mu \mathrm{m}$ & $w_{t g y}$ & $20 \mu \mathrm{m}$ \\
\hline$w_{b g y}$ & $10 \mu \mathrm{m}$ & $l_{m g y}$ & $2,000 \mu \mathrm{m}$ \\
\hline$l_{c g y}$ & $500 \mu \mathrm{m}$ & $w_{m g y}$ & $1,500 \mu \mathrm{m}$ \\
\hline$l_{t g y}$ & $200 \mu \mathrm{m}$ & $d_{c g y}$ & $4 \mu \mathrm{m}$ \\
\hline
\end{tabular}

Table 7. Dimensions of Z-axis gyroscope.

\begin{tabular}{|c|c|c|c|}
\hline$l_{b g z}$ & $520 \mu \mathrm{m}$ & $l_{m g z}$ & $2,000 \mu \mathrm{m}$ \\
\hline$w_{b g z}$ & $10 \mu \mathrm{m}$ & $l_{c g z}$ & $80 \mu \mathrm{m}$ \\
\hline$d_{c g z}$ & $4 \mu \mathrm{m}$ & $l_{c g z}$ & $160 \mu \mathrm{m}$ \\
\hline
\end{tabular}

Figure 9. Layout configuration of the mechanical sensing element chip. (a) The layout configuration after global optimization. (b) The final layout configuration after device optimization.

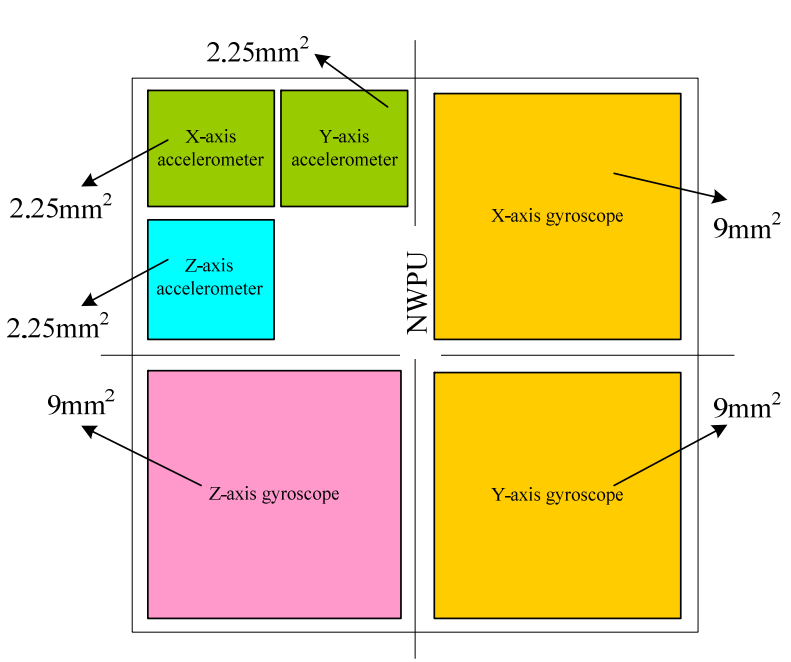

(a)

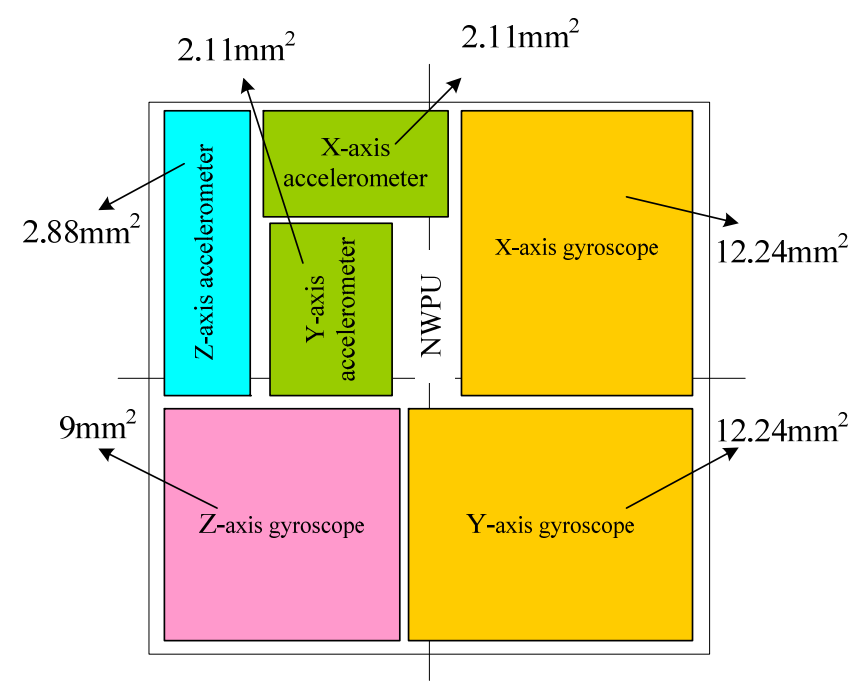

(b) 
Table 8. Comparison of the equivalent side length with parameters adjusted.

\begin{tabular}{|c|c|c|}
\hline & Global Layout Configuration & Final Layout Configuration \\
\hline $\mathrm{X} / \mathrm{Y}$-axis Accelerometer & $1,500 \mu \mathrm{m}$ & $1,452 \mu \mathrm{m}$ \\
\hline Z-axis Accelerometer & $1,500 \mu \mathrm{m}$ & $1,697 \mu \mathrm{m}$ \\
\hline $\mathrm{X} / \mathrm{Y}$-axis Gyroscope & $3,000 \mu \mathrm{m}$ & $3,498 \mu \mathrm{m}$ \\
\hline Z-axis Gyroscope & $3,000 \mu \mathrm{m}$ & $3,000 \mu \mathrm{m}$ \\
\hline
\end{tabular}

\section{Interface Circuit Design for Inertial Sensors}

Various interface circuit design schemes exist. Here, we took some typical ones for accelerometers (Figure 10) and gyroscopes (Figure 11) in the MIMU. However, there are six different single-axis sensors in MIMU; the various signals will experience crosstalk. Therefore, special design in the interface circuit chip is needed to suppress the crosstalk. In addition to the necessary shielding, the proper choice of interface circuit frequency for the different sensors is also very helpful in suppressing crosstalk. Usually the noises of the operational amplifiers decrease with a higher frequency. Thus, we set the frequency of the interface circuit for gyroscopes to be higher than that of the accelerometers because the gyroscope is less sensitive than the accelerometer. Such a configuration is very helpful in reducing noise in the circuit.

Figure 10. The interface circuit block diagram for the accelerometers.

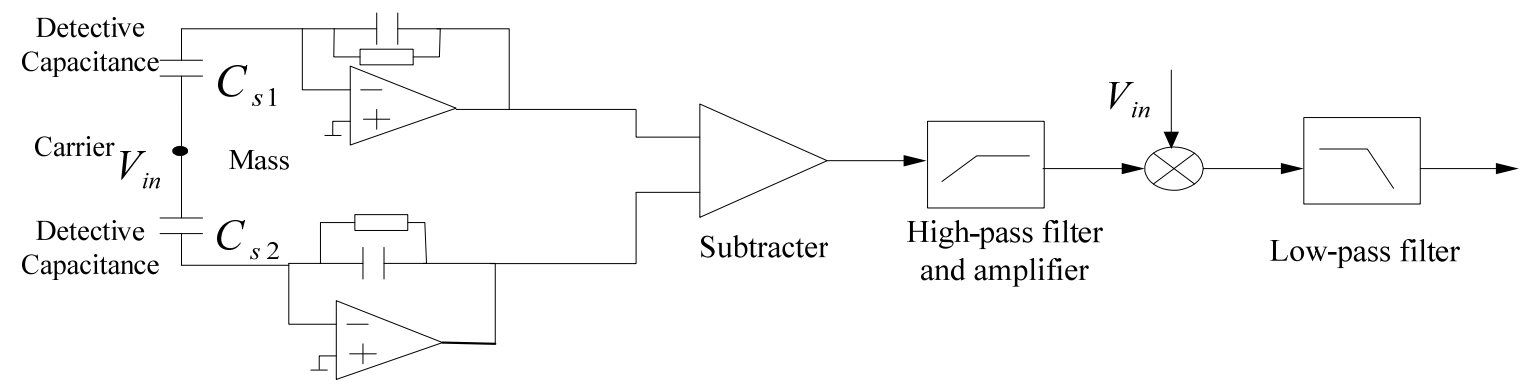

Figure 11. The interface circuit block diagram for the gyroscopes.

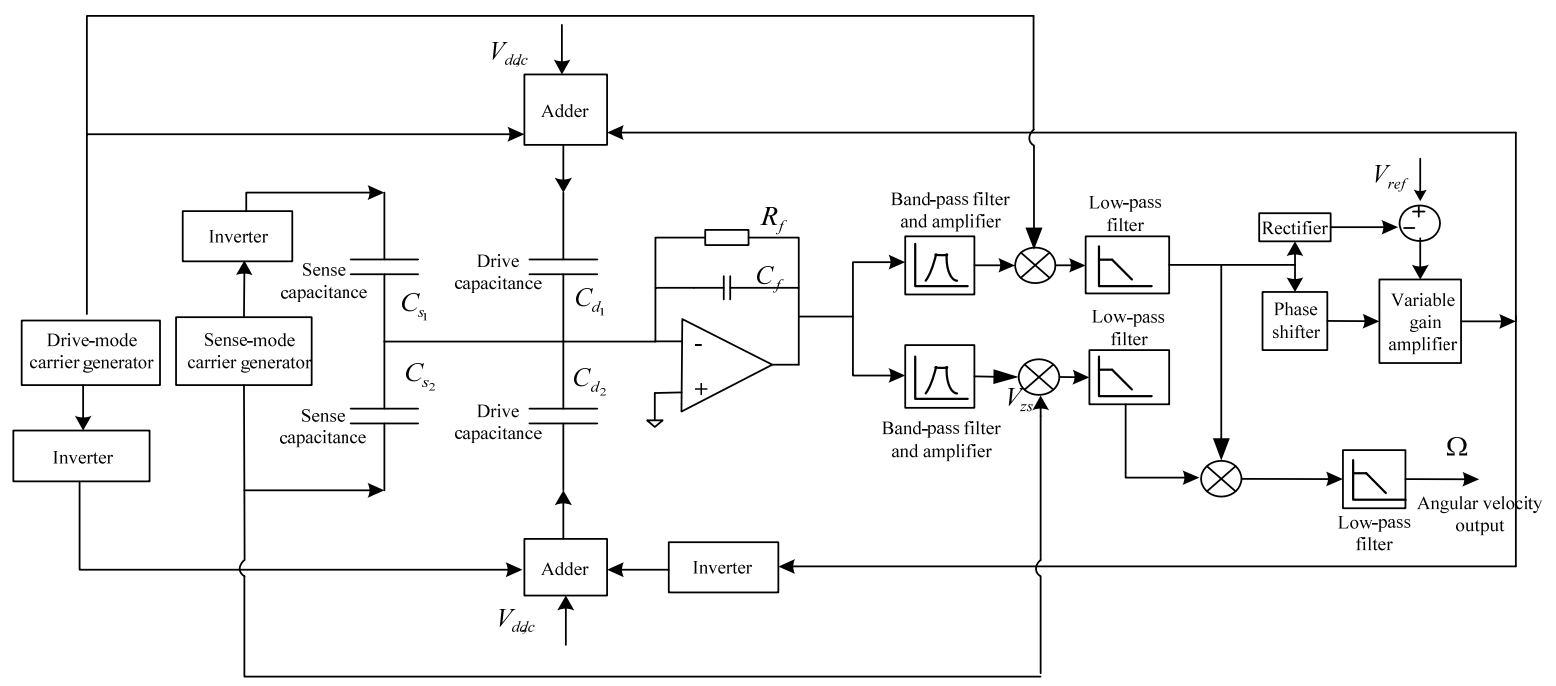


As in the mechanical chip, a proper layout in the circuit chip can suppress crosstalk. The circuits for the gyroscopes were placed next to the circuits for the accelerometers. Furthermore, the circuits with similar frequencies were separated. The final layout configuration of the interface circuit chip is shown in Figure 12.

Figure 12. Layout configuration of the interface circuit chip in MIMU.

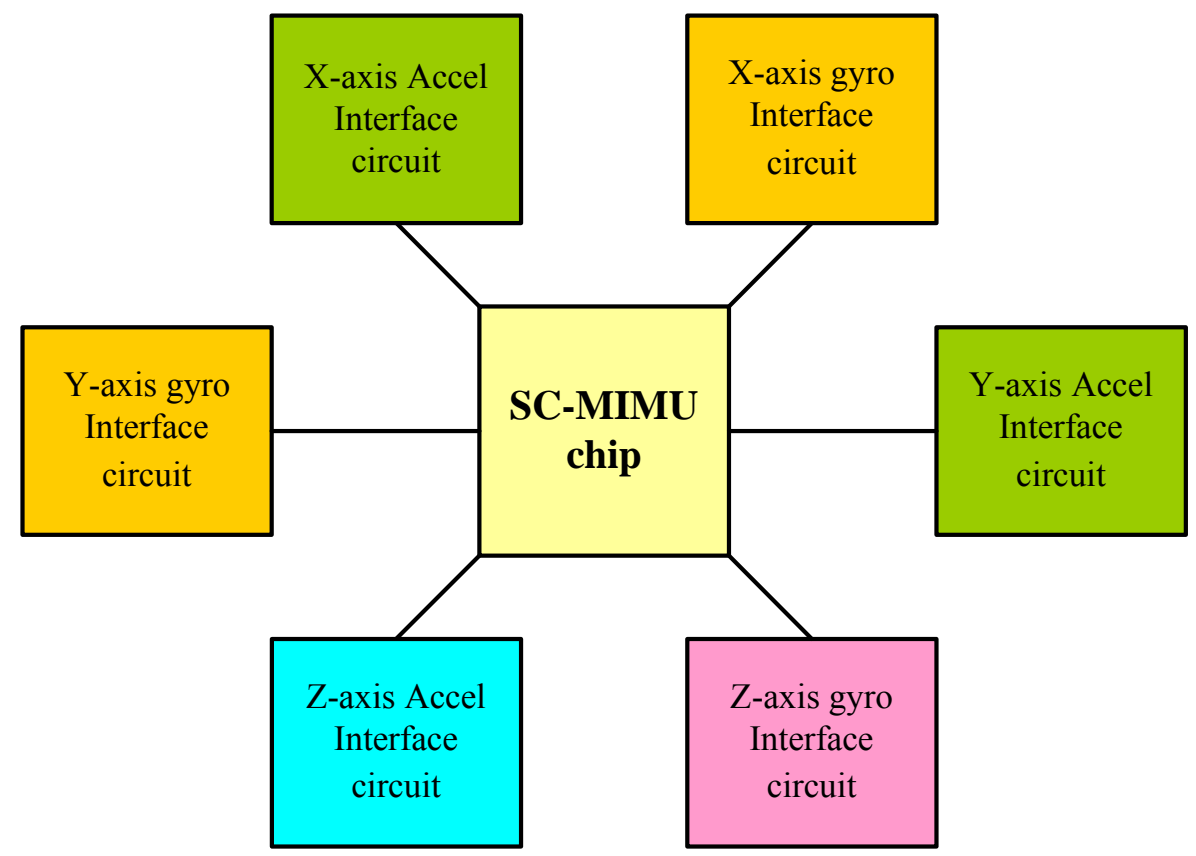

\section{Fabrication and Test of the Bulk-Micromachined MIMU}

We used the process flow shown in Figure 2 to fabricate the designed MIMU. The fabricated chip is shown in Figure 13. We used the circuit board shown in Figure 14 to test the MIMU.

The frequency responses of the six sensors are shown in Figure 15. It can be observed that the resonant frequencies of the $\mathrm{X} / \mathrm{Y}$-axis accelerometer and $\mathrm{Z}$-axis accelerometer are about 2,506 $\mathrm{Hz}$ and 2,084 Hz, respectively. The resonant frequencies of the drive mode and sense mode for the $\mathrm{X} / \mathrm{Y}$-axis gyroscope are $4,032 \mathrm{~Hz}$ and $4,048 \mathrm{~Hz}$, respectively. The resonant frequencies of the drive mode and sense mode for the $\mathrm{Z}$-axis gyroscope are $5,090 \mathrm{~Hz}$ and $5,132 \mathrm{~Hz}$, respectively.

The scale factor plots of the six sensors are shown in Figure 16. It can be seen that the scale factors of the X/Y-axis accelerometer and Z-axis accelerometer are about $213.3 \mathrm{mV} / \mathrm{g}$ and $226.9 \mathrm{mV} / \mathrm{g}$, respectively. The big nonlinearity exists just because the rough test method based on a triangle ruler. The accelerometers were tiled $0^{\circ}, 30^{\circ}, 45^{\circ}, 60^{\circ}, 90^{\circ}, 270^{\circ}, 300^{\circ}, 315^{\circ}, 330^{\circ}, 360^{\circ}$, respectively, through a triangle ruler to generate multiple acceleration input. The scale factors of the $\mathrm{X} / \mathrm{Y}$-axis gyroscope and Z-axis gyroscope are about $2.2 \mathrm{mV} / \% / \mathrm{s}$ and $10.8 \mathrm{mV} / \% / \mathrm{s}$, respectively.

Plots of the Allan variance analysis for the gyroscopes are shown in Figure 17. It can be seen that the bias stability of the $\mathrm{X} / \mathrm{Y}$-axis gyroscope and the $\mathrm{Z}$-axis gyroscope are about 2,135 deg/h and $80 \mathrm{deg} / \mathrm{h}$, respectively.

The noise floors of the six sensors are shown in Figure 18. It can be observed that the power spectral densities of the noise for $\mathrm{X} / \mathrm{Y}$-axis accelerometers, Z-axis accelerometers, $\mathrm{X} / \mathrm{Y}$-axis 
gyroscopes, and Z-axis gyroscopes are $258.7 \mu \mathrm{V} / \sqrt{\mathrm{Hz}}, 247.8 \mu \mathrm{V} / \sqrt{\mathrm{Hz}}, 692.4 \mu \mathrm{V} / \sqrt{\mathrm{Hz}}$, and $86.3 \mu \mathrm{V} / \sqrt{\mathrm{Hz}}$, respectively. Consequently the resolutions of $\mathrm{X} / \mathrm{Y}$-axis accelerometers, Z-axis accelerometers, $\mathrm{X} / \mathrm{Y}$-axis gyroscopes, and Z-axis gyroscopes are $0.0012 \mathrm{~g} / \sqrt{\mathrm{Hz}}, 0.0011 \mathrm{~g} / \sqrt{\mathrm{Hz}}$, $0.314^{\circ} / \mathrm{s} / \sqrt{\mathrm{Hz}}$, and $0.008^{\circ} / \mathrm{s} / \sqrt{\mathrm{Hz}}$, respectively.

It is obvious that the performance is far from the navigation level [38]. The major reason for this low performance lies in the capacitive detection circuit. There are a significant amount of noise that reduces the capacitance detection capability far below the expected $10^{-19} \mathrm{~F}$. If the interface circuit were improved, the performance of the sensors would be much better. Another phenomenon is that the performance of the $\mathrm{X} / \mathrm{Y}$-axis gyroscope is much worse than that of the Z-axis gyroscope, primarily because the big squeeze film damping for the out-of-plane motion in the sense mode of the X/Y-axis gyroscope is packaged at one atmosphere. The large damping greatly reduced the quality of the sense mode. In the future, the $\mathrm{X} / \mathrm{Y}$-axis gyroscope needs to be improved further to obtain a better performance, e.g., by using a larger layout area or a smaller resonant frequency, if identical performance is required for all three gyroscopes.

Figure 13. Photo of the final MIMU.

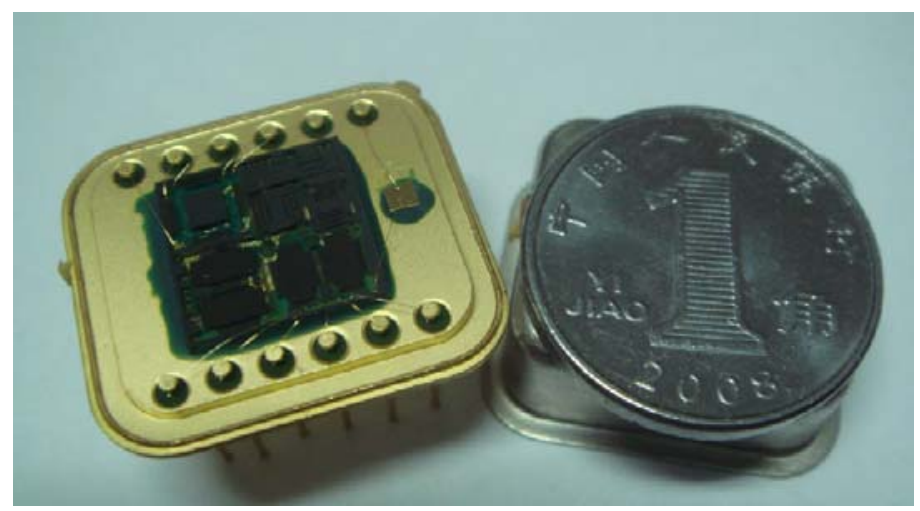

Figure 14. Photo of a test circuit board for MIMU.

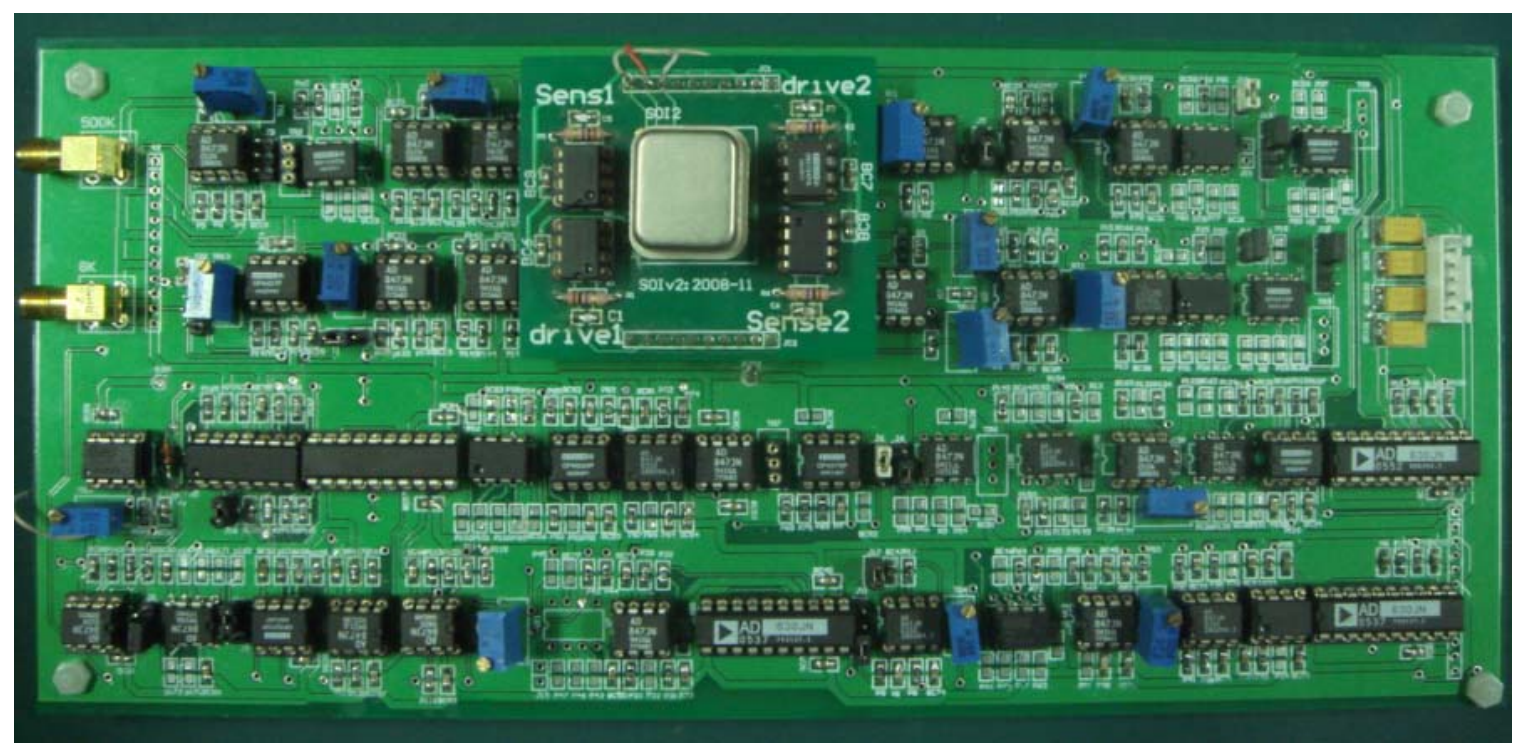


Figure 15. The frequency responses of the six inertial sensors. (a) $X / Y$-axis accelerometer; (b) Z-axis accelerometer; (c) X/Y-axis gyroscope in drive mode; (d) X/Y-axis gyroscope in sense mode; (e) Z-axis gyroscope in drive mode; (f) Z-axis gyroscope in sense mode.

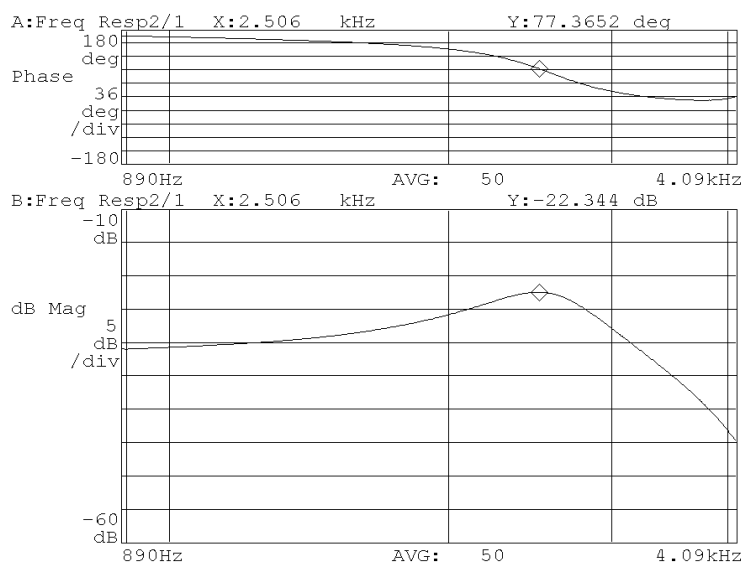

(a)
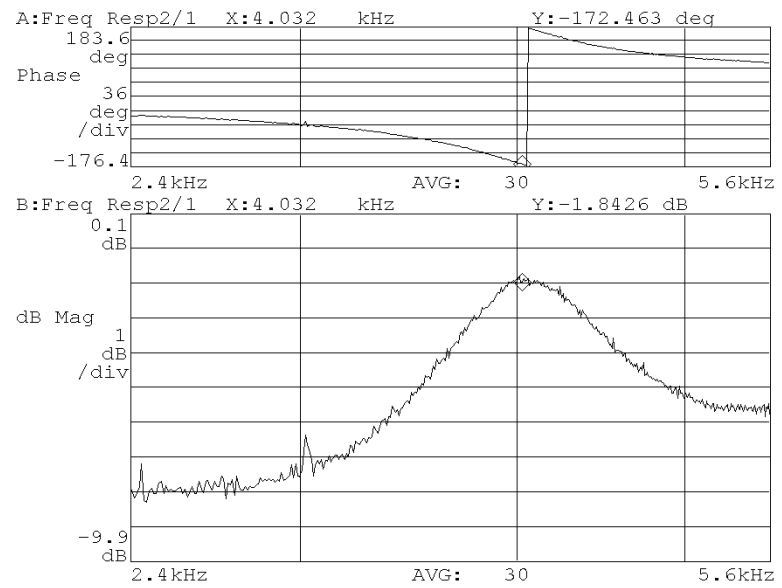

(c)
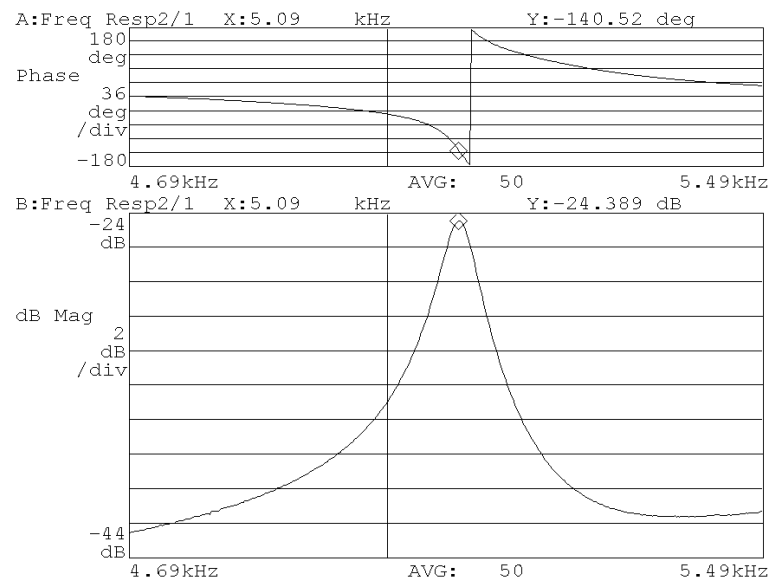

(e)
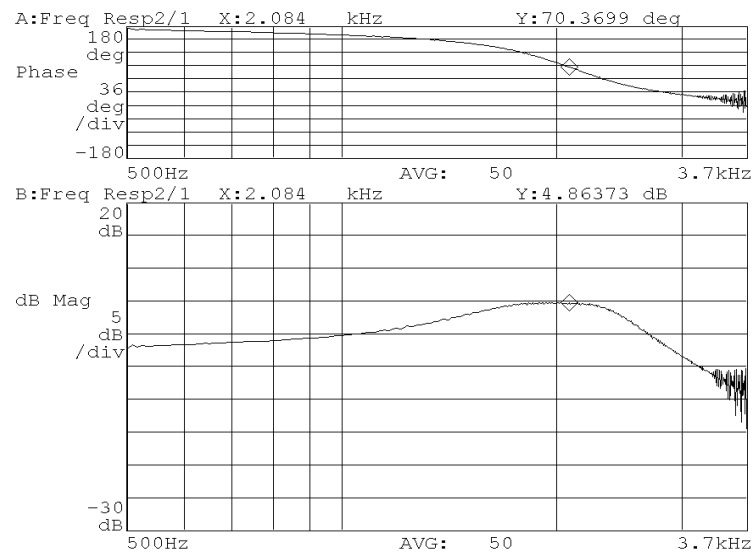

(b)
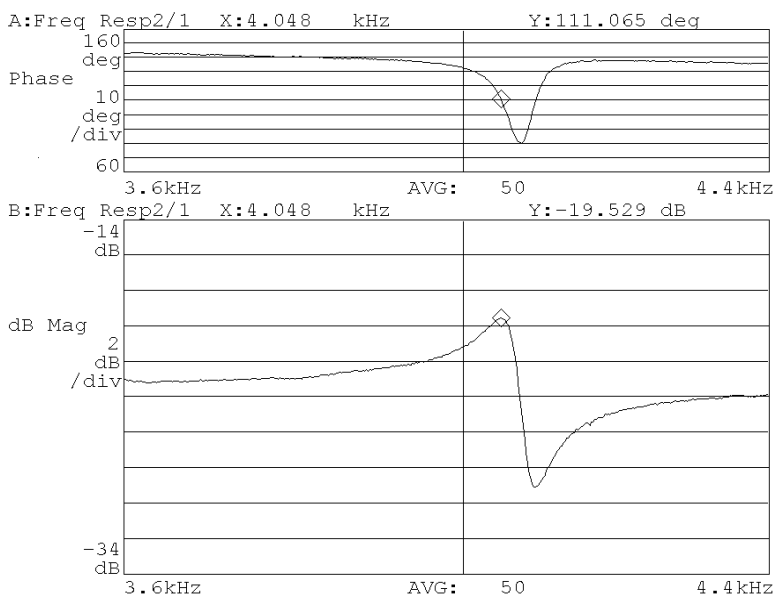

(d)
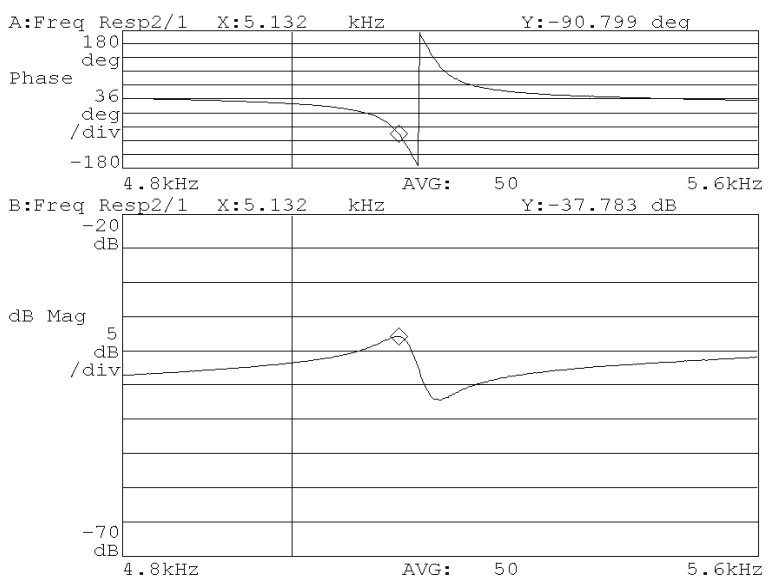

(f) 
Figure 16. Scale factors for the six sensors in the MIMU. (a) $X / Y$-axis accelerometer; (b) Z-axis accelerometer; (c) X/Y-axis gyroscope; (d) Z-axis gyroscope.

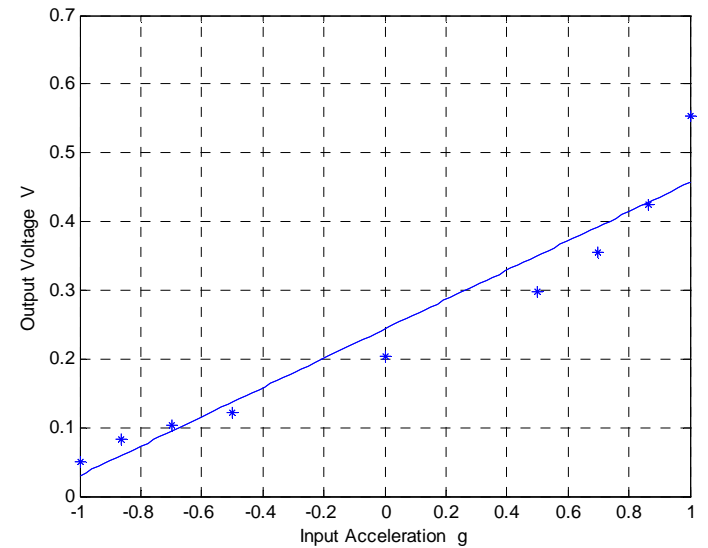

(a)

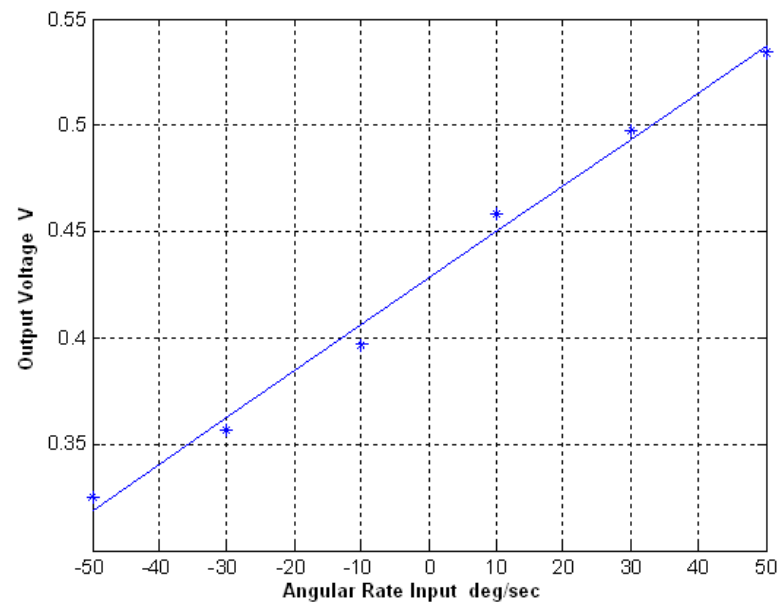

(c)

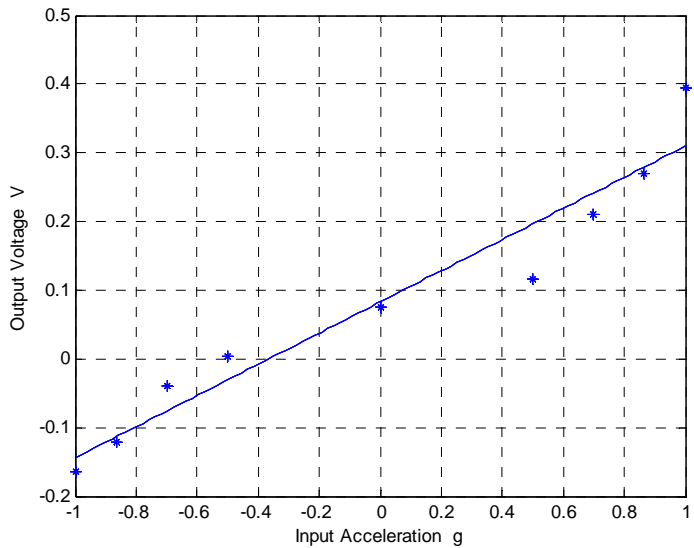

(b)

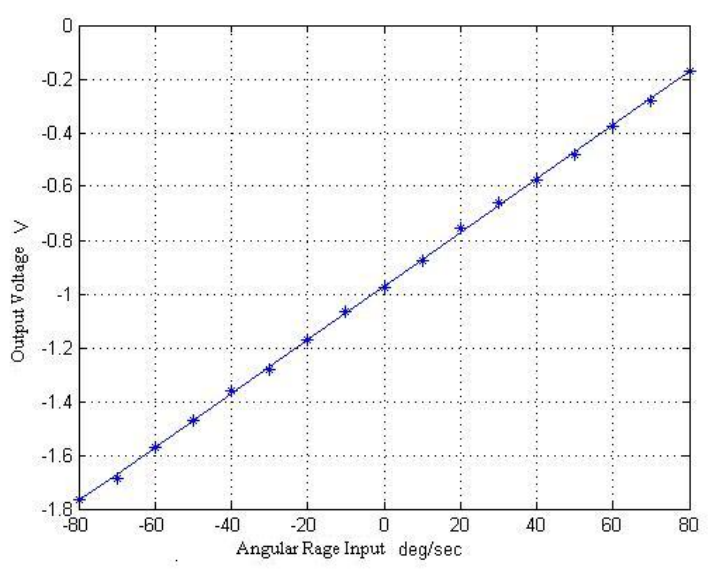

(d)

Figure 17. Plots of Allan variance for gyroscopes. (a) $\mathrm{X} / \mathrm{Y}$-axis gyroscope; (b) Z-axis gyroscope.

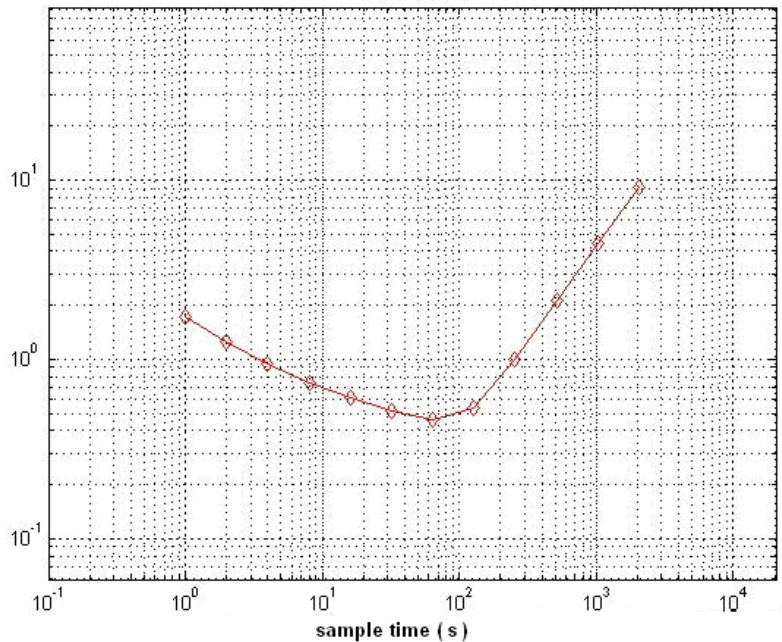

(a)

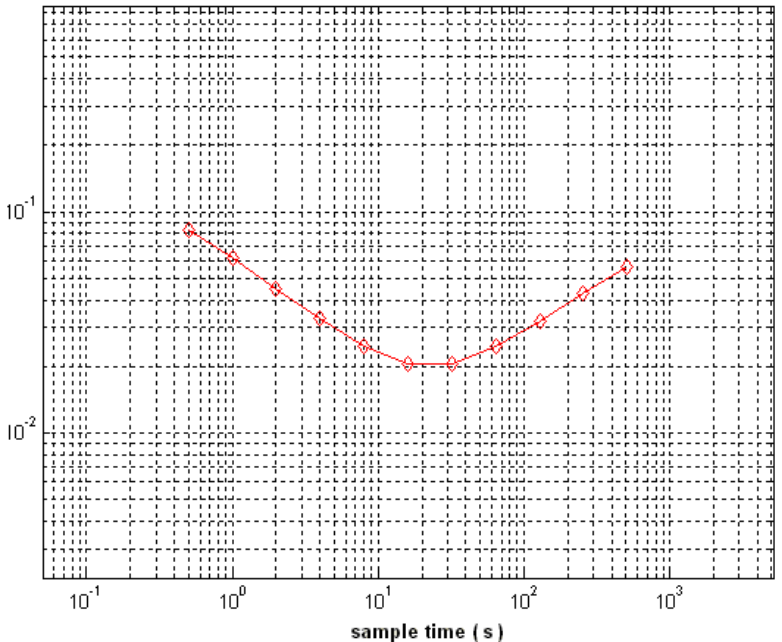

(b) 
Figure 18. The noise floors of the six sensors in the MIMU. (a) $X / Y$-axis accelerometer; (b) Z-axis accelerometer; (c) X/Y-axis gyroscope; (d) Z-axis gyroscope.

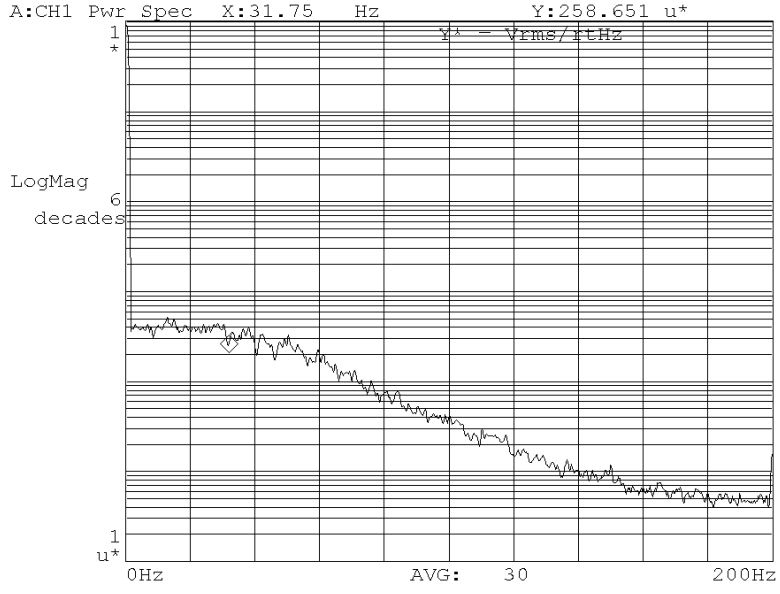

(a)

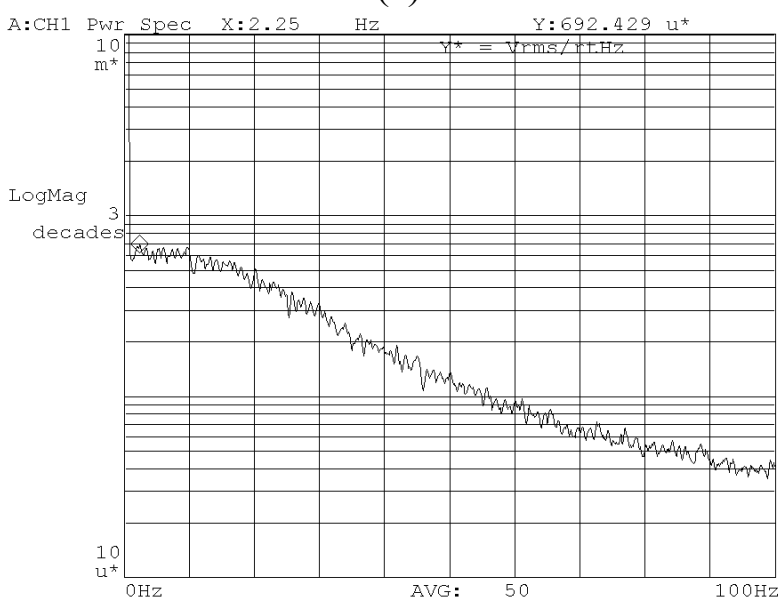

(c)

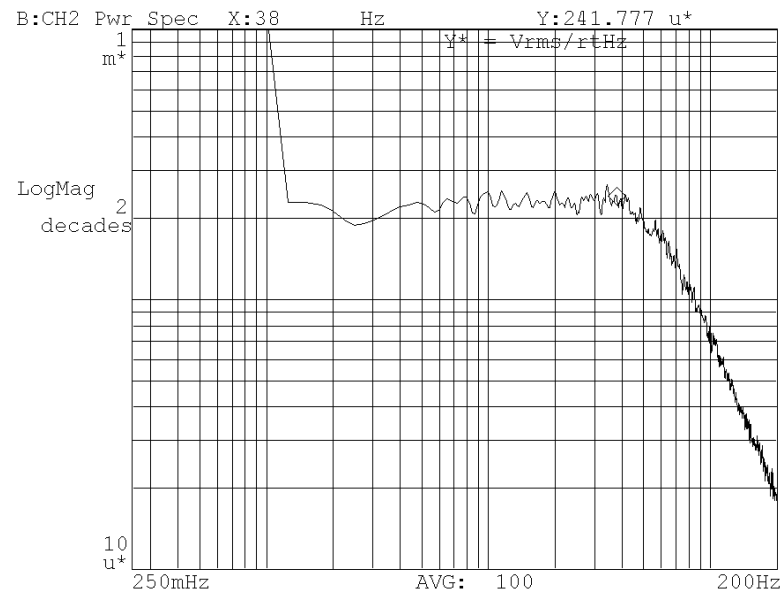

(b)

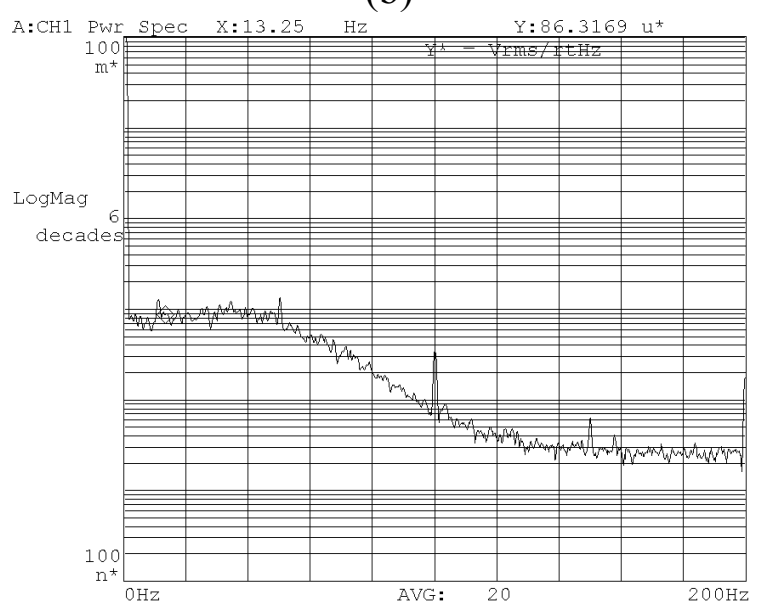

(d)

\section{Conclusions}

In this paper, we demonstrated a miniature bulk micromachined MIMU; a detailed design, the fabrication process and testing were all discussed for the first time. The proposed global area optimization approach is proved to be very effective to determine the layout configuration of the six single-axis sensors in the mechanical element chip. Moreover, the widely used common geometry patterns are also proved to effectively alleviate the RIE lag effect in bulk micromachining process. The test results show that the current MIMU achieves medium accuracy. With an improved interface circuit, this technology can yield better performance than the surface micromachined MIMU.

\section{Acknowledgements}

The authors gratefully acknowledge Chinese Hi-Tech Research and Development Program's financial support (Contract No.2009AA04Z320), Xi'an Applied Materials Innovation Fund of China's financial support (No. XA-AM-200801), and the Chinese National Science Foundation's financial support (Contract No. 60976087). 


\section{References and Notes}

1. Kourepenis, A.; Connelly, J.; Sitomer, J. Low cost MEMS inertial measurement unit. In Proceedings of ION NTM, San Diego, CA, USA, January 26-28, 2004; pp. 246-251.

2. John, J.D.; Vinay, T. Novel concept of a single-mass adaptively controlled tri-axial angular rate sensor. IEEE Sens. J. 2006, 6, 588-595.

3. Nan, C.T. Fabrication and analysis of a micro-machined tri-axis gyroscope. J. Micromech. Microeng. 2008, 18, 150-164.

4. Nan, C.T.; Chung, Y.; Chih, C.L. Design and dynamics of an innovative micro gyroscope against coupling effects. Microsyst. Technol. 2008, 14, 295-306.

5. Zou, Q.; Tan, W.; Eun, S.K.; Loeb, G.E. Single-and tri-axis piezoelectric-bimorph accelerometers. J. Microelectromech. Syst. 2008, 17, 45-57.

6. Kwon, K.J.; Park, S.K. A bulk-micromachined three-axis accelerometer using silicon direct bonding technology and polysilicon layer. Sens. Actuat. A-Phys. 1998, 66, 250-255.

7. Junseok, C.; Kulah, H.; Ajafi, K. A monolithic three-axis micro-g micromachined silicon capacitive accelerometer. J. Microelectromech. Syst. 2005, 14, 235-242.

8. Qu, H.W.; Fang, D.Y.; Xie, H.K. A monolithic CMOS-MEMS 3-axis accelerometer with a low-noise, low-power dual-chopper amplifier. IEEE Sens. J. 2008, 8, 1511-1518.

9. Allen, J.; Kinney, R.; Sarsfield, J.; Daily, M.; Ellis, J.; Smith, J. Integrated micro electromechanical sensor development for inertial applications. In Proceedings of IEEE PLANS, Rancho Mirage, CA, USA, April 20-23, 1998; pp. 9-16.

10. Hao, L.; Fedder, G.; Carley, L. Integrated multiple-device IMU system with continuous-time sensing circuitry. In Proceedings of IEEE International Solid-State Circuits, San Francisco, CA, USA, February 2003; pp. 191-205.

11. Yong, Z.; Guizhen, Y.; Jie, F.; Xuesong, L.; Jian, Z.; Yangyuan, W. Post-CMOS process for high-aspect-ratio monolithically integrated single crystal silicon microstructures. In Proceedings of Tranducers'05, Seoul, Korea, June 5-9, 2005; pp. 1130-1133.

12. Xie, H.K.; Zhu, X.; Gabriel, K.J.; Fedder, G.K. Post-CMOS processing for high-aspect-ratio integrated silicon microstructures. J. Microelectromech. Syst. 2002, 11, 93-101.

13. Alandry, B.; Dumas, N.; Latorre, L.; Mailly, F.; Nouet, P. A CMOS multi-sensor system for 3D orientation determination. In Proceedings of IEEE Computer Society Annual on VLSI, Montpellier, France, April 7-9, 2008; pp. 57-62.

14. Xie, H.K.; Fedder, G.K. Fabrication, characterization, and analysis of a DRIE COMS-MEMS gyroscope. IEEE Sens. J. 2003, 3, 622-631.

15. Qu, H.W.; Xie, H.K. Process development for CMOS-MEMS sensors with robust electrically isolated bulk silicon microstructures. J. Microelectromech. Syst. 2007, 16, 1152-1161.

16. Ajit, S.M.; Mohammad, F.Z.; Mark, Z.C.; Farrokh, A.Z. A 0.1/HR bias drift electronically matched tuning fork microgyroscope. In Proceedings of IEEE MEMS, Tucson, AZ, USA, January 13-17, 2008; pp. 6-9.

17. Weinberg, M.S.; Kourepenis, A. Error sources in in-plane silicon tuning-fork MEMS gyroscopes. J. Microelectromech. Syst. 2006, 15, 479-491. 
18. Cardarelli, D. An integrated MEMS inertial measurement unit. In Proceedings of IEEE PLNS, Los Angeles, CA, USA, April 15-18, 2002; pp. 314-319.

19. Chang, H.L.; Yuan, W.Z.; Cui, J.Q.; Jiang, Q.H.; Zhang, P.; Li, Q.; Yang, F. One Bulk Micromachined Single-Chip Inertial Measurement Unit. In Proceedings of IEEE Sensors, Daegu, Korea, October 22-25, 2006; pp. 1485-1488.

20. Gottscho, R.A.; Jurgensen, C.W. Microscopic uniformity in plasma etching. J. Vac. Sci. Technol. B. 1992, 10, 2133-2147.

21. Jansen, H.; De Boer, M.; Wiegerink, R.; Tas, N.; Smulders, E.; Neagu, C.; Elwenspoek, M. RIE lag in high aspect ratio trench etching of silicon. Microelectron. Eng. 1997, 35, 45-50.

22. Hwang, G.S.; Giapis, K.P. On the origin of the notching effect during etching in uniform high density plasmas. J. Vac. Sci. Technol. B. 1997, 15, 70-87.

23. Cozma, A.; Puers, B. Characterization of the electrostatic bonding of silicon and pyrex glass. J. Micromech. Microeng. 1995, 5, 98-102.

24. Srinivasa-Murthy, C.; Wang, D.; Beaudoin, S.P.; Bibby, T.; Holland, K.; Cale, T.S. Stress distribution in chemical mechanical polishing. Thin Solid Films 1997, 308-309, 533-537.

25. Innam, L.; Gil, H.Y.; Jungyul, P.K.; Seonho, S.K.; Kukjin, C.B.; Kyo-Il, L. Development and analysis of the vertical capacitive accelerometer. Sens. Actuat. A-Phys. 2005, 119, 8-18.

26. Junseok, C.; Haluk, K.A.; Khalil, N.F. A hybrid silicon-on-glass (SOG) lateral microaccelerometer with CMOS readout circuitry. In Proceedings of IEEE MEMS, Las Vegas, NV, USA, January 20-24, 2002; pp. 623-626.

27. Yazdi, N.; Ayazi, F.; Najafi, K. Micromachined inertial sensors. Proc. IEEE 1998, 86, 1640-1659.

28. Yazdi, N.; Najafi, K.; Salian, A.S. A high-sensitivity silicon accelerometer with a folded-electrode structure. J. Microelectromech. Syst. 2003, 12, 479-486.

29. Selvakumar, A.; Najafi, K. A high-sensitivity z-axis capacitive silicon microaccelerometer with a torsional suspension. J. Microelectromech. Syst. 1998, 7, 192-200.

30. Lee, I.; Yoon, G.H.; Park, J.; Seok, S.; Chun, K.; Lee, K. Development and analysis of the vertical capacitive accelerometer. Sens. Actuat. A 2005, 119, 8-18.

31. Bernstein, J.; Cho, S.; King, A.T.; Kourepenis, A.; Mace, P.; Weinberg, M. A micromachined comb-drive tuning fork rate gyroscope. In Proceedings of IEEE MEMS, Fort Lauderdale, FL, USA, February 7-10, 1993; pp. 143-148.

32. Chen, Y.; Jiao, J.; Xiong, B.; Che, L.; Li, X.; Wang, Y. A novel tuning fork gyroscope with high Q-factors working at atmospheric pressure. Microsyst. Technol. 2005, 11, 111-116.

33. Said, E.A.; Kivanc, A.; Tayfun, A. A high-performance silicon-on-insulator MEMS gyroscope operating at atmospheric pressure. Sens. Actuat. A-Phys. 2007, 135, 34-42.

34. Kim, J.; Park, S.; Kwak, D.; Ko, H.; Cho, D.D. An x-axis single-crystalline silicon microgyroscope fabricated by the extended SBM process. J. Microelectromech. Syst. 2005, 14, 444-455.

35. Acar, C.; Shkel, A.M. Inherently robust micromachined gyroscopes with 2-DOF Sense-Mode oscillator. J. Microelectromech. Syst. 2006, 15, 380-387.

36. Yuan, W.Z.; Chang, H.L.; Li, W.J. Application of an optimization methodology for multidisciplinary system design of microgyroscopes. Microsyst. Technol. 2006, 12, 315-323. 
37. Ongkodjojo, A.; Francis, E.H.T. Global optimization and design for microelectromechanical systems devices based on simulated annealing. J. Micromech. Microengineer. 2002, 12, 878-897.

38. Beeby, S.; Ensell, G.; Kraft, M.; White, N. MEMS Mechanical Sensors, 1st ed.; Artech House: Boston, MA, USA/London, UK, 2004; pp. 174-175.

(C) 2010 by the authors; licensee Molecular Diversity Preservation International, Basel, Switzerland. This article is an open-access article distributed under the terms and conditions of the Creative Commons Attribution license (http://creativecommons.org/licenses/by/3.0/). 